\title{
THE EFFECT OF FUELWOOD HARVESTING ON THE LIVELIHOOD OF RURAL HOUSEHOLD IN MOYAMBA DISTRICT SOUTHERN SIERRA LEONE
}

\author{
PATRICK KARGBO
}

Njala University, Sierra Leone

DOI: 10.46609/IJAER.2020.v06i03.001 URL: https://doi.org/10.46609/IJAER.2020.v06i03.001

\begin{abstract}
The study was to assess the situation of fuelwood harvesting on the livelihood of rural households in Moyamba District southern Sierra Leone. With such the specific objectives were; To determine the extent of fuelwood harvesting among households in the research area. Assess the Knowledge of rural households on the climate issue. The extent to which household access climate change-related extension services in the research area. The communities were selected purposively. The respondents were selected randomly. One hundred and fifty respondents were surveyed. The study revealed that $63.3 \%$ of the total population does not access extension services. $53.3 \%$ of the total population harvest fuelwood for firewood every week. On the average households are spending 11 more minutes rep trip now to collect fuelwood, this shows that deforestation is on the rise. The study recommends that extension workers should receive training on climate change-related issues. Besides, other alternatives for cooking should be made available to rural households.
\end{abstract}

Keywords: firewood, livelihood, household, natural resources, income generation, consumption, population, alternatives etc

\section{INTRODUCTION}

Agriculture is an important sector in developing countries in general and Africa in particular (Makonnen et.al, 2015). People living in such countries are also heavily dependent on natural resources such as fuelwood for their livelihood when natural resources are degraded rural households respond in different ways to cope with the scarcity of the resources. Among several options, these households use their labor to cope with the increasing scarcity of natural resources.

Globally, fuelwood is the principal energy source for over 2 billion, primarily poor people (Sangay, 2011) and fuelwood harvesting accounts for over $54 \%$ of total annual wood removal 
International Journal of Agriculture and Environmental Research

ISSN: $2455-6939$

Volume: 06, Issue: 03 "May-June 2020"

from forests. Approximately 1.7 billion of fuelwood and charcoal were produced globally in 2004 (Wangchuk et.al 2013). And wood-based fuels comprise about $80 \%$ of total household energy consumption and $35 \%$ of total energy use in developing countries.

Wood harvesting is the third most important economic activity for the inhabitants of the forestdependent area, after farming and animal husbandry (Yunana, 2013). In the past, wood harvesting in developing countries was mainly for domestic consumption, and it was mostly women who gathered the dry branches and trunks of trees and shrubs for fuelwood (Awah 2005). Today the situation has changed, increased commercialization of the sector has led to the widespread harvest of both dead and live branches and trunks by men and women.

The majority of forests, by their very nature, are located within rural and frequently remote areas. Typically this means that such areas are underdeveloped in terms of infrastructure, government services, markets, and jobs. It is not surprising, therefore, that communities living in and adjacent to savannas and forests are characterized by seemingly high levels of poverty and limited livelihood opportunities (Shackle ton, 2004). Rural households are highly dependent on forest resources for subsistence foods and materials as well as for cash income. Over 90\% of rural households depend on forests to meet their household energy requirements.

The total extraction of wood and non-wood forest products average $30.6 \%$ of the total household production per annum (Bwalya,2011).

The forest sector in Africa plays an important role in the livelihoods of many communities and the economic development of many countries. This is particularly so in Western, Central, and Eastern Africa where there is considerable forest cover. Africa has a high per capita forest cover at 0.8 ha per person compared to 0.6 ha globally (Sebukeera et.al, 2005).

In Africa and many developing countries, there is an inextricable link between the forest resource and the livelihoods of the rural communities. More than $80 \%$ of the rural population in sub-Saharan Africa is poor and traditionally relies on forests for most of their livelihoods including fuelwood and timber as well as other non-timber forest products and Fuelwood provides the main source of the total household energy requirements in Africa with the consumption varying from country to country for example 85\% in Mozambique, $76 \%$ Zambia, 91\% Tanzania and 14\% in South Africa (Kalaba, 2010).

It is clear that in the short and medium-term wood, complemented by farm residues, will remain the only affordable fuel for the majority of the population in West Africa. There is also no doubt that this great demand for fuelwood and charcoal exerts considerable pressure on the wood resources of this country, giving rise to serious and widespread concern on the sustainability of 
International Journal of Agriculture and Environmental Research

ISSN: 2455-6939

Volume: 06, Issue: 03 "May-June 2020"

supply of wood energy with a demand for charcoal that covers up to $70 \%$ of the entire national requirement for such commodity (Drigo et el, 2013).

Fuelwood is almost certainly the earliest traded forest commodity in Sierra Leone. Before even the establishment of the Freetown settlement, in the 17th century passing European ships frequented the Freetown peninsula to purchase firewood bundles (among other items) from the Temne and Sherbo communities living there (Munro, 2011). He further states that Historical records suggest that soon after the initial settlement and growth of Freetown, much of the town's firewood supplies started to come from outside the Peninsula area. During the same period, the colonial government also put out its tenders for firewood, inviting applications to supply mangrove wood for public buildings. As Freetown continued to grow, the railway became important for supplying the city with firewood from medium to long distances, especially before World War Two. While firewood was mostly sold informally by hawkers around Freetown at this time there were at least two official depots on Freetown's waterfront in 1939 selling the commodity (Munro et.al 2011). Firewood also had some limited commercial value in other urban centers in Sierra Leone during this period. As well, it is likely that other larger centers such as BoTown and possibly Kenema Town also had some modest commercial trade in firewood during this period (Munro, 2011).

After Sierra Leone 1991-2001 civil war, the trade-in firewood became increasingly commercialized, with large numbers of villages near highways or urban centers becoming involved in harvesting and commercially trading the commodity.

However, Overall Bo and Kanama towns have the most complex markets in the southern region of Sierra Leone. Bundles of fuelwood are sold at various price points between Le 200 and Le 5,000 depending on the size and number of the sticks in the bundles (Kebbay,2011).

In Bo Town, the smaller vendors bring their supplies on foot from their farms (usually around 30 to 40 medium-sized bundles per month) and mid-size larger vendors hire others to carry their supplies (usually around 80 bundles per month) while the largest vendors hire trucks to bring in around 100 to 200 bundles per month. There are a couple of very large scale vendors in Bo town that truck in over 500 bundles each month. In contrast, all vendors in Kanama town tend to operate at a medium scale, hiring trucks to bring in 40 to 50 bundles of firewood each month (Kondey2011).

Similarly, the vendors operating in Moyamba town and Kailahun town are simply residents of nearby villages who bring supplies from their farms each day (around 30-40 bundles a month) and sell them for between Le 500 - 2,000 (Kpagoi, 2011). 
Rural household in southern Region of Sierra Leone procure a wide variety of products from forest resources to meet their basic needs for food security (Shackleton, 2000). They are also important natural assets for rural households, providing both subsistence and market-oriented livelihood strategies. For example, in south-eastern of Sierra Leone, the average value of woodland goods collected was observed to be $30 \%$ of the average gross cash income per household per year (Campbell et al., 2002). The expanding commercialization of many woodland products also provides rural households with a range of market-oriented woodland livelihood opportunities (Serra et.al, 2003). The harvesting of woodland products is widely recognized as an integral component of the rural livelihoods throughout the Moyamba District, offering goods for both household consumption and income generation. The primary factors influencing household energy consumption are the number of individuals in the household and household income (Sangay, 2011).

\section{STATEMENT OF PROBLEM}

The Southern Region of Sierra Leone is the most forested area in Sierra Leone.

There is numerous problem associated recently in this part of the country due to the lack of knowledge of the effect fuelwood harvesting cause on the livelihood of rural household in Moyamba District. Some of this problem facing recently is the heavy involvement of rural people in deforestation which have to affect agricultural activities by exposing the soil to erosion that lead the soil to lost of nutrient and fertility that contribute to the low output of crops. It has reduced the watershed areas and cause pollution in the environment that has resulted in the greenhouse effect.

The continues harvesting of fuelwood in the forested areas has also signaled a negative impact on the tourist attraction because most of the Animal that is usually found in these forests have been forced to migrate to another part of the country. It has also affected the planting time for most farmers because they have used to determine it by the weather condition.

\section{AIM AND SPECIFIC OBJECTIVES OF THE RESEARCH}

\section{Aim}

This research aims to assess the effect of fuelwood harvesting on the livelihood of rural households in Moyamba District, Southern Sierra Leone.

\section{OBJECTIVES OF THE RESEARCH}

The Objectives of the research are as follows. 
1. To describe the Characteristics of rural households that depend on fuelwood harvesting in the research area.

2. To determine the extent of fuelwood harvesting among households in the research area

3. Assess the Knowledge of rural households on climate issues.

4. The Extent to which household access extension services in the research area

\section{RESEARCH HYPOTHESIS}

The study will be carried out by testing the following hypotheses

HO: There is a significant effect of fuelwood harvesting on the livelihoods of rural households in the Moyamba District.

HA: There is no significant effect of fuelwood harvesting on the livelihood of rural households in the Moyamba District.

\section{JUSTIFICATION OF THE STUDY}

Human livelihood in most rural areas in Sierra Leone is highly dependent on farming activities, but the subsistence form of Agricultural practiced by rural farmers can barely feed themselves and their immediate family members. People hence seek for other complementary alternatives. One such alternative has been fuelwood harvesting mostly for charcoal production.

Additionally, the increasing demand for this product has led to an increase in the quantities harvested. Dramatic changes have been occurring on human livelihoods, in terms of sociocultural and economic parameters. Despite these changes, no know publication has based its research on the impact of fuelwood harvesting on human livelihoods of residents of Moyamba District in Sierra Leone. It is therefore relevant to conduct research that will reveal relevant results and recommendations that will greatly impact the research world, farmers, and decisionmakers.

\section{SCOPE OF THE STUDY}

This study was conducted mainly in Kori, Kamajei, and lower Banta chiefdom because there is massive harvesting of fuelwood in those areas. According to the study the following was of our target we investigated; Characteristics of a rural household, the extent of fuelwood harvesting, knowledge of rural household on climate change, and household access to extension services.

\section{LIMITATIONS}

There were limitations encountered during the study. These were; Respondent was not will to divulge information: some respondent is reluctant to respond to the interview schedule because a 
lot of their time had been wasted in the past by researchers on interviews without any perceived benefits. These problems made it necessary for the researchers to work through some stakeholders so that they will discuss it with me. Getting respondents for questioning: it was also difficult to get the respondent to spear their productive time or leisure time for questioning. they were either very busy taking-off for a farm in the morning or very tired in the evening after a whole day work on their farms. This, therefore, put heavy pressure on data collection to approximately adjust to the respondent's daily schedule and interviews them when it was convenient.

\section{METHODOLOGY}

\section{Description of the study area.}

\section{Moyamba District}

This study will be conducted in the Moyamba district. Moyamba district on the other hand borders the Atlantic Ocean in the west, both Portloko and Tonkolili districts to the north, Bo district, and Bonthe district in the south. Moyamba District is a district in the southern province of Sierra Leone, with a population of 260,910 in the 2004 census. It's the capital and the largest city in Moyamba. The other major towns include; Njala, Rotifunk, and Shenge. The district is the largest in the southern province by geographical area, occupying a total of $6,902 \mathrm{~km}(2,665 \mathrm{sq}$ miles) and comprises fourteen chiefdoms.

The main economic activities including mining (retile and bauxite), fishing, rice growing, and oil palm production. The dominant ethnic groups in the district are the Mende, Shebro, and Limba

\section{Research Design}

The research design used for this study will be a non- experimental design. The simple form of non- experimental design is a statistical survey. This design is considered appropriate for this research because of the nature of the objectives and the type of data will be collected which is descriptive. Its weakness is usually minimized through appropriate survey methods using randomization and proper data collection instrument by:

1. Ensuring that the questions to be answered are clear and not misleading

2. Getting respondents to answer questions thoughtfully and honestly

3. Getting a sufficient number of questionnaires completed and returned so that meaningful analysis can be made.

\section{Source of Data}


Volume: 06, Issue: 03 "May-June 2020"

The data for this study will be collected from one main source. I.e. the primary data were the farmers will be contacted.

\section{Population sample Size and Sampling Procedure}

\section{Population}

The population for this study comprises of the household of selected chiefdoms in Moyamba District

\section{Sample Size}

The sample size for this study was determined to base on Yamane (1967) sample size determination procedure. Using this procedure, a total of 150 households was selected from among the total population

\section{Sample Procedure}

A two-stage sampling technique was used to select the sample respondents. The first stage was the purposive selection of the project area. The second stage was also the selection of the respondent. A sample random sampling technique was used to select a total number of one hundred and fifty (150) as a sample for the survey.

\section{Data Collection}

A survey questionnaire was chosen for the collection of information from the farmers for this study to achieve the study objectives. This study preferred questionnaire because of the ease of administration and scoring, besides the results being readily analyzed. The items on the questionnaire were developed based on the objectives of the study, Observation methods were also used by looking at the quantity of fuelwood they harvested pa day. The questionnaire was tested to check its contact, construct, and face validity. Contact Validity ensured that the content of the instrument contained an adequate sample of the domain of content it represented. Face validity looked at the format of the instrument that includes aspects like the clarity of printing, font size and type, adequacy of workspace, and appropriateness of language among others. Construct validity determined the nature of the psychological construct or characteristics being measured by the instrument. The research supervisor and two other experts in measurement and evaluation were also consulted to help in review to ensure the instrument accurately measured the variables is intended to measure in the study. To ensure the reliability of the instrument, the pre-test methods were employed. By the pre-test methods, it means the instrument was administered on a pilot sample of an interval of two weeks between first and second administration. The instrument was administered to the household by the researcher himself. An appointment for the administration of a questionnaire to the respondents was booked with the 
assistance from village elders. The instrument was administered to the household by enumerators to collect the required information and their responses recorded accordingly. The study focused mainly on household heads for the survey questionnaire to cater for uniformity of the data collection process.

\section{Data Analysis}

The Data collected was entered and analyzed by simple descriptive analysis and Econometric models using statistical package for social scientists (SPSS) version 16 software. The software was chosen because it is the most used package for analyzing survey data. The software has the following advantages: it can easily be used to analyze multi-response questions, cross-section, and time series analysis and cross-tabulation;(i.e. relate two sets of variables) and it can also be used alongside Microsoft excel and world.

\section{Descriptive Statistics}

Descriptive statistics such as frequency counts; percentages, proportions, and means were used to analyze the data. Frequency tables and figures were developed to display the results obtained from the research analysis.

\section{PRESENTATION OF RESULT AND DISCUSSION OF FINDINGS}

The results of this study are presented and discussed in this chapter. The interpretation is based on the set objectives. Findings were also explained in the context of related studies and reviewed the literature

\section{Characteristics of rural households}

One of the objectives of this study was to determine the characteristics of households in kori, kamejei, and lower Banta on the effect of fuelwood harvesting on the livelihood of rural households in the moyamba district.

\section{Gender of respondents}

Gender may determine what role men and women play in the development programs in rural communities. It also dictates which technology to design for any particular community. Hence, the gender situation in the study area was investigated and the results are presented below Gender distribution of respondents. 


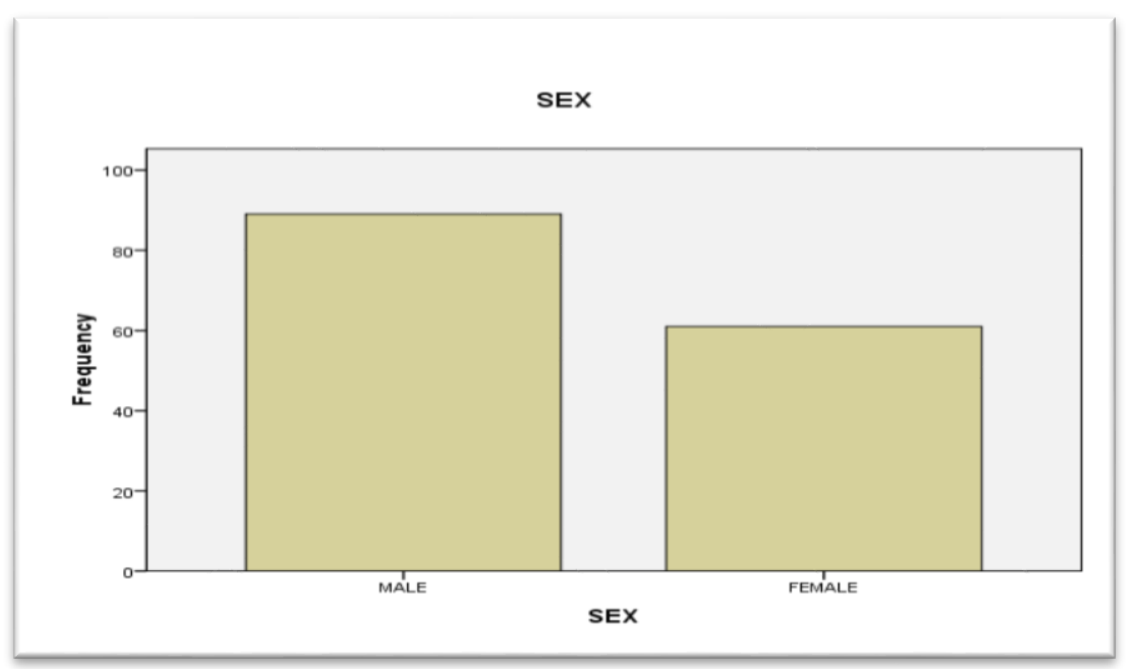

Source: survey 2015

Figure 1: Showing Gender distribution of respondents in the study area

Figure 2: shows that $59.3 \%$ of the respondents interviewed were male and $40.7 \%$ were female. This reveals that in the study area, the male gender is the highest participants in fuelwood harvesting

\section{Age of Respondents}

Age is a measure of maturity and determines the rate of an individual in any society. Literature tends to suggest that it also determines the adoption capacity of the individual. The age distribution of respondents is presented in figure 3 


\section{Age distribution of respondents}

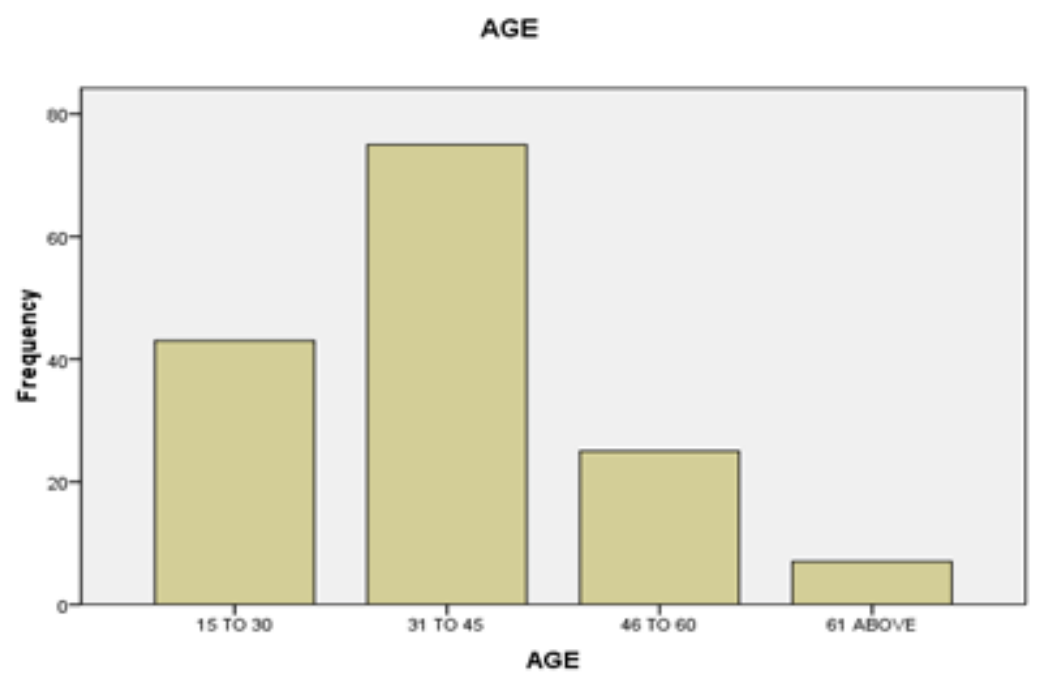

Source: Survey 2015

\section{Figure 2: Age Distribution of Respondents in the Study Area}

Figure 2: Shows that the average age of the respondents was 31 years old. However, the age varies from 15 and 78 years, with the highest concentration being in the age bracket of $(50.0 \%)$. This represents the active group in fuelwood harvesting it is clearly shown that fuelwood harvesting was in the middle age class. This has a positive bearing on their ability to harvesting fuelwood.

\section{Marital status of the respondent}

Marriage confers the status and responsibility of the individual. Usually, a person's marital status is considered relative to his or her social status, level of responsibility, and moral behavior. 


\section{Marital Status of Respondents}

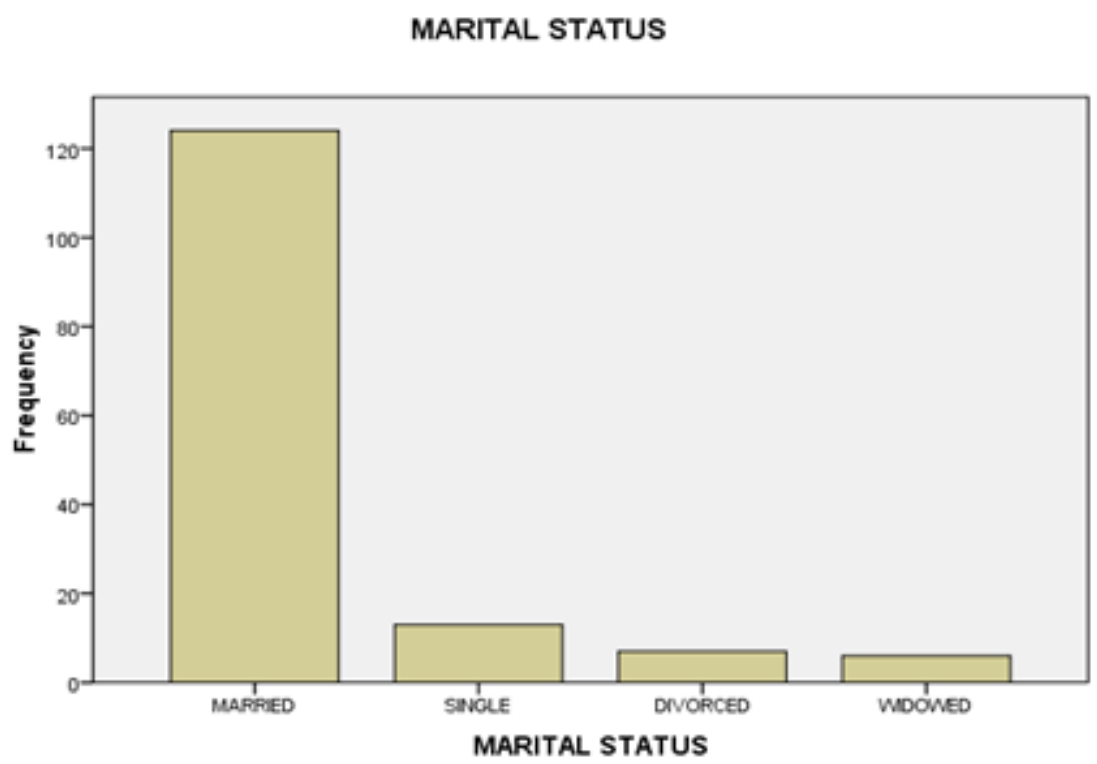

Source: survey 2014

Figure 3: Distribution of respondent showing marital status in study Area

Figure 3: the marital profile of the respondent showed that about $82.7 \%$ were married, $8.7 \%$ single, $4.7 \%$ divorced, and $4.0 \%$ widowed. The $83.7 \%$ of married have an impact on the household to produce not only for sale but to feed his family. This was expected to have a positive effect on fuelwood harvesting on the livelihood of a rural household since He/she needs to feed more mouths. 


\section{Academic Level of Respondent}

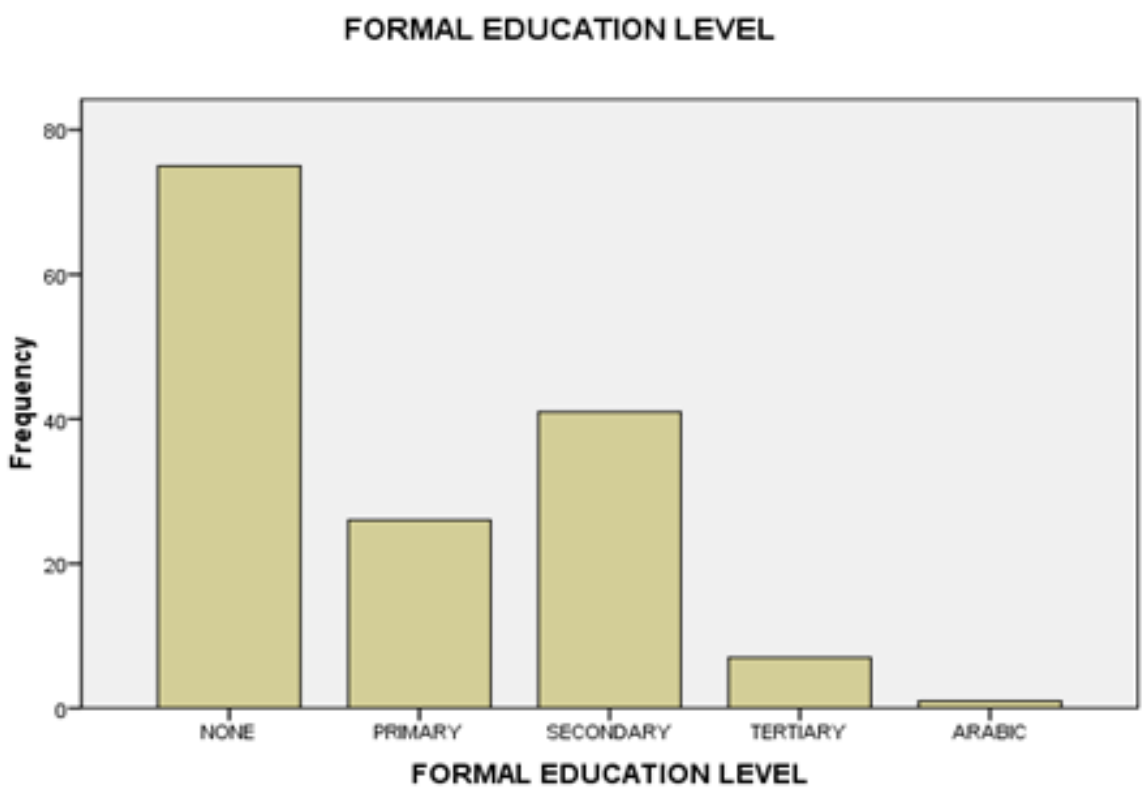

Source: Survey 2014

Figure 4: Academic level of Respondent in the study area

Figure 4: The level of awareness and adoption of the effect of fuelwood harvesting are affected by the literacy status of farmers. But according to literature, the sustainability of agricultural production is largely dependent on the action of the farmers and their decision making abilities given the level of knowledge and information that is available to them(Rahman,2003).50.0\% of the household heads did not go to school at all while $27.3 \%$ were fortunate to acquired secondary school education, $17.3 \%$ attained primary school level, $4.7 \%$ tertiary education and $7 \%$ attained Arabic education. 


\section{Head of Household}

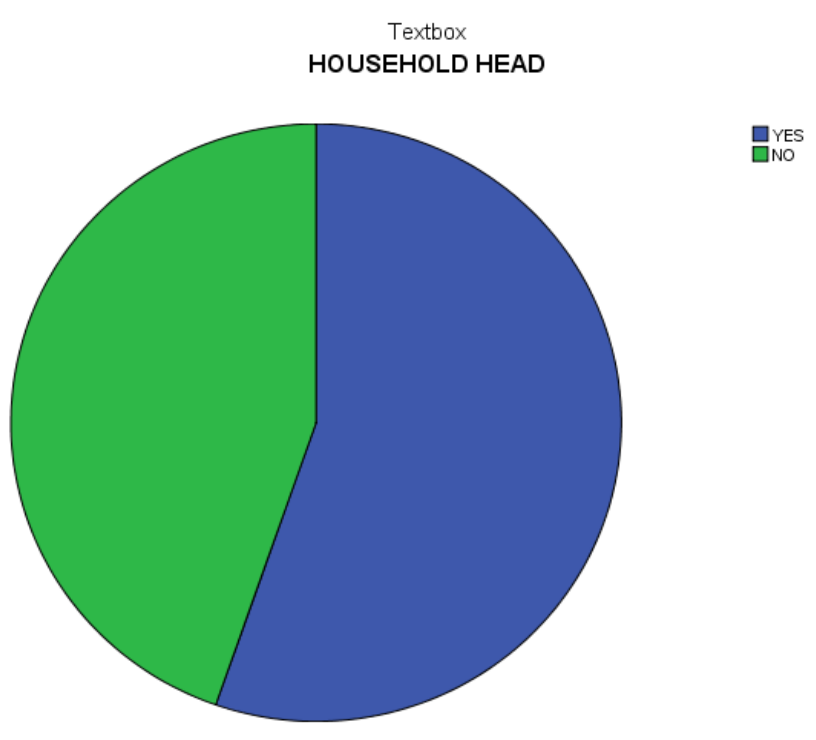

Figure 5: Household Head of Respondent in the study area

Figure 5: Among the respondents that were interviewed 55.3\% were household heads of their family and $44.7 \%$ could either be wife, son, sister, mother-in-law, father-in-law, etc. An increase in the number of household heads tends to encourage them to divert from fuelwood harvesting.

\section{SIZE OF HOUSEHOLD}

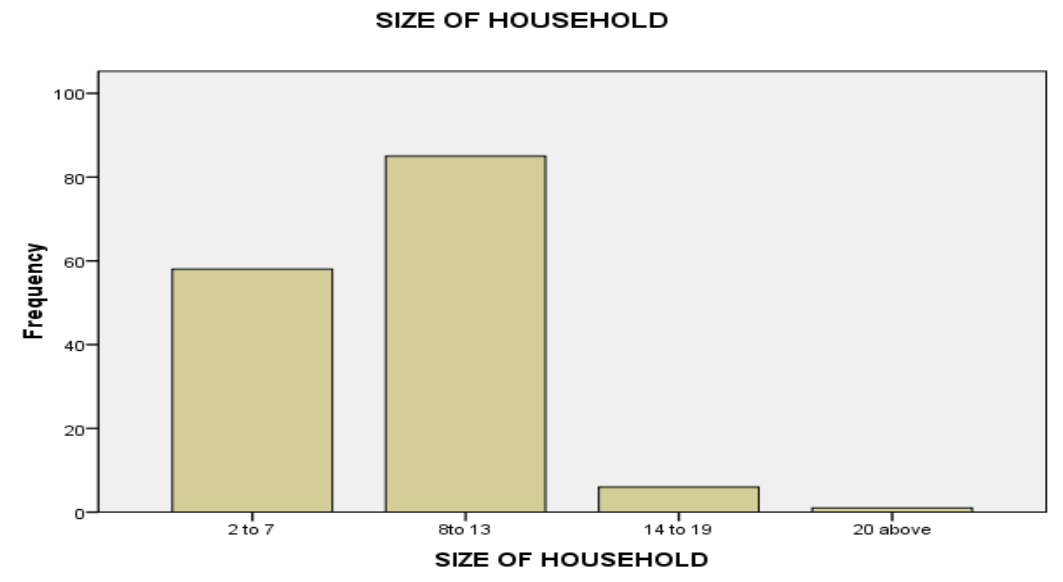

Source: survey 2015

Figure 6: Showing size of households of respondents in the study area 
Figure 6: shows that $56.7 \%$ of the respondents had 8-13 household members with the highest majority, $38.7 \%$ of the respondents had $2-7$ household members with the second majority.4.0\% of them have 14-19 household members and 7\% have 20 upwards household members downwards

\section{Relationship with the household head}

\section{RELATIONSHIP WITH HOUSEHOLD HEAD}

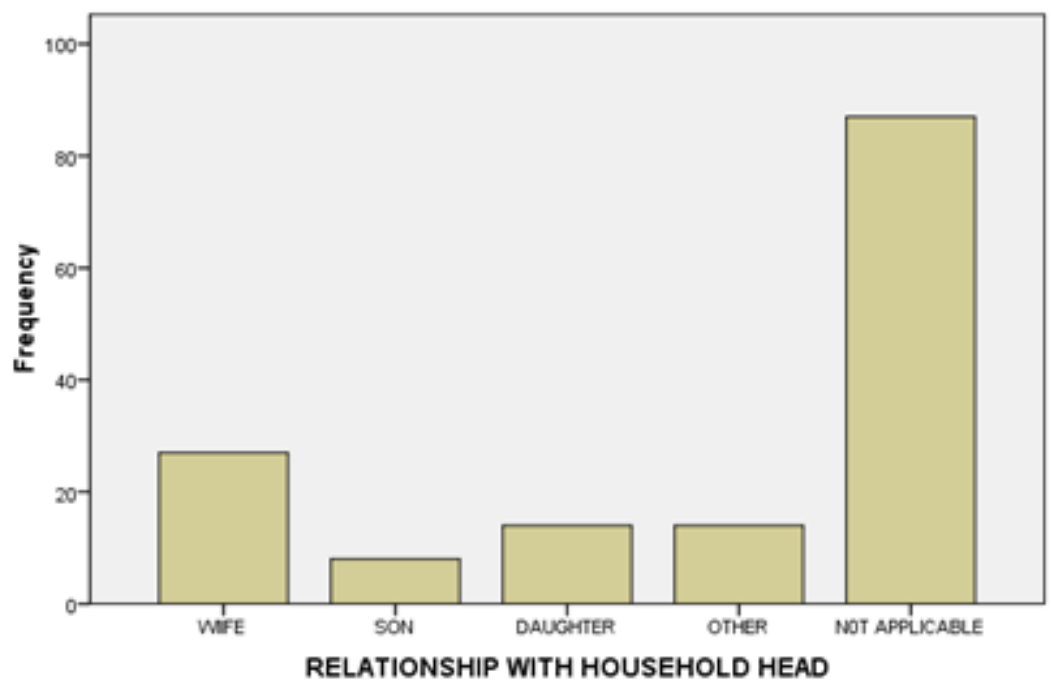

Source: survey 2015

Figure 7: showing the Relationship with the household head in the study area

Figure 7: Among the respondents that were interviewed $18.0 \%$ were the wife of household heads, $5.0 \%$ was the son of household heads, $9.3 \%$ daughter of household head $9.3 \%$ could either be sister, mother-in-law, father-in-law, tenant $58.0 \%$ not applicable means they are household head and the question is not relevant to them. 


\section{Source of livelihood}

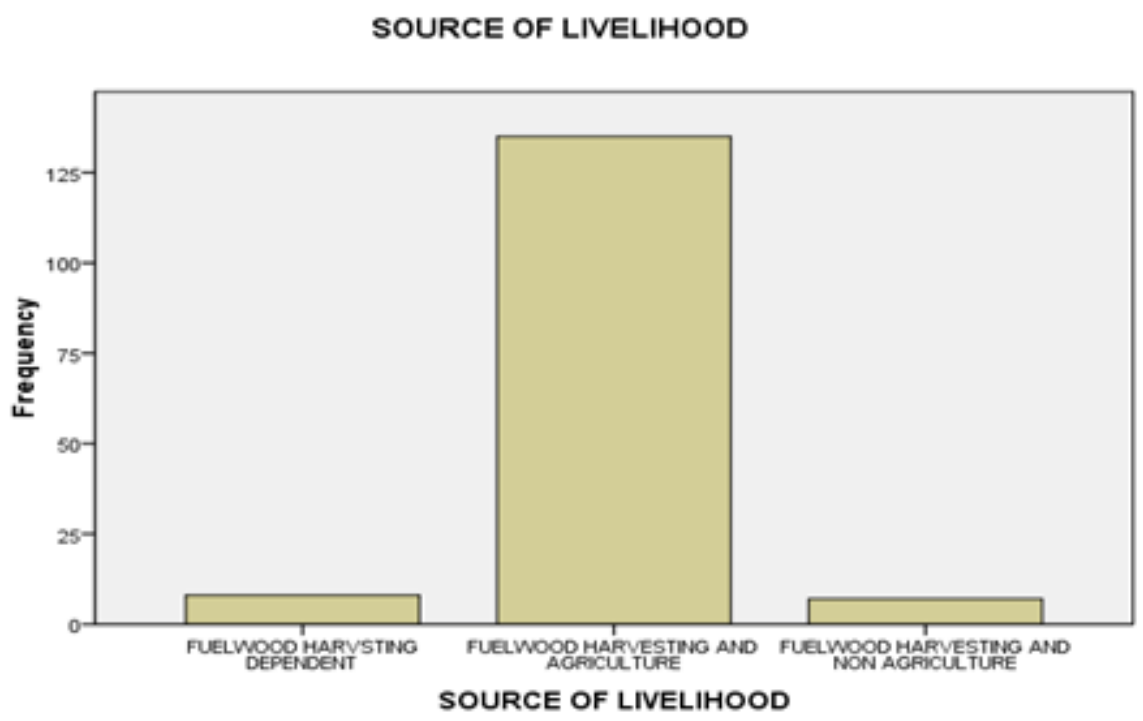

Source: survey 2015

Figure 8: Showing the source of your livelihood in the study area

Figure 9: The data clearly show that $90.0 \%$ of the respondent depend on fuelwood harvesting and agriculture, $5.3 \%$ of the respondent are fuelwood dependent and $4.7 \%$ are fuelwood harvesting and non-agriculture-dependent. 
Estimate monthly income from all sources

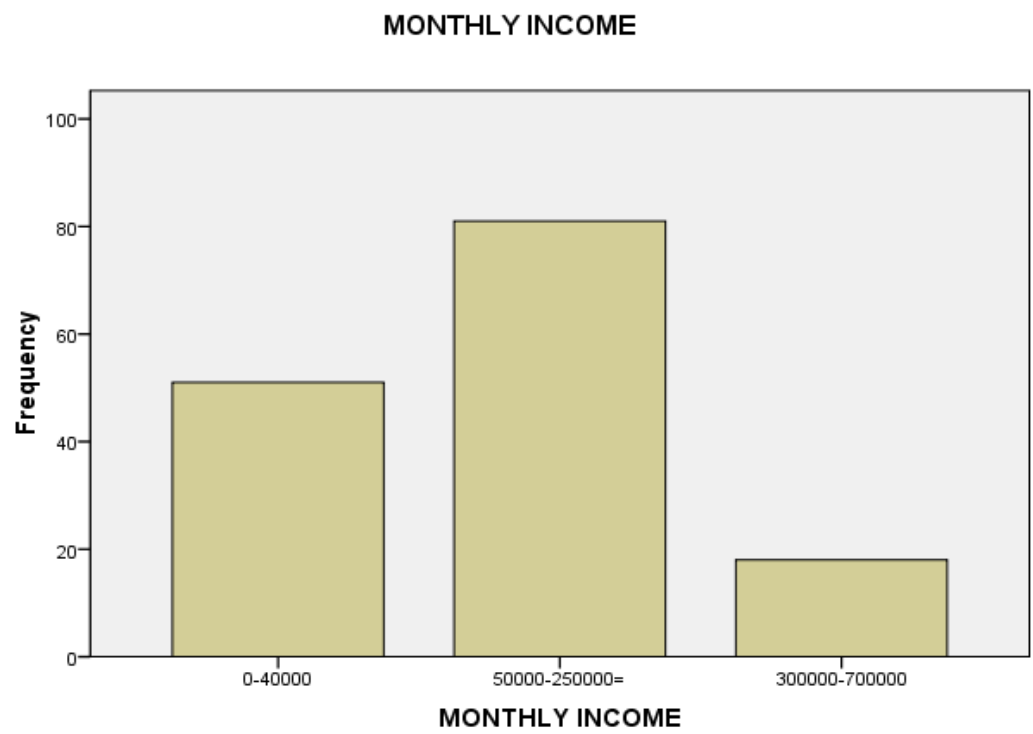

Source: survey 2015

Figure 9: Showing the estimate monthly income from all sources from the respondent

Figure 9: The data clearly show that $54.0 \%$ of the respondents' monthly source of income is less than equal to $50,000-250,000$ Leone. $34.0 \%$ of the respondents' monthly source of income is less than equal to $0-40,000$ Leone and $12 \%$ of the respondents' monthly source of income is less than equal to 300,000-700,000 Leone. 


\section{Duration of staying in this community in the study area}

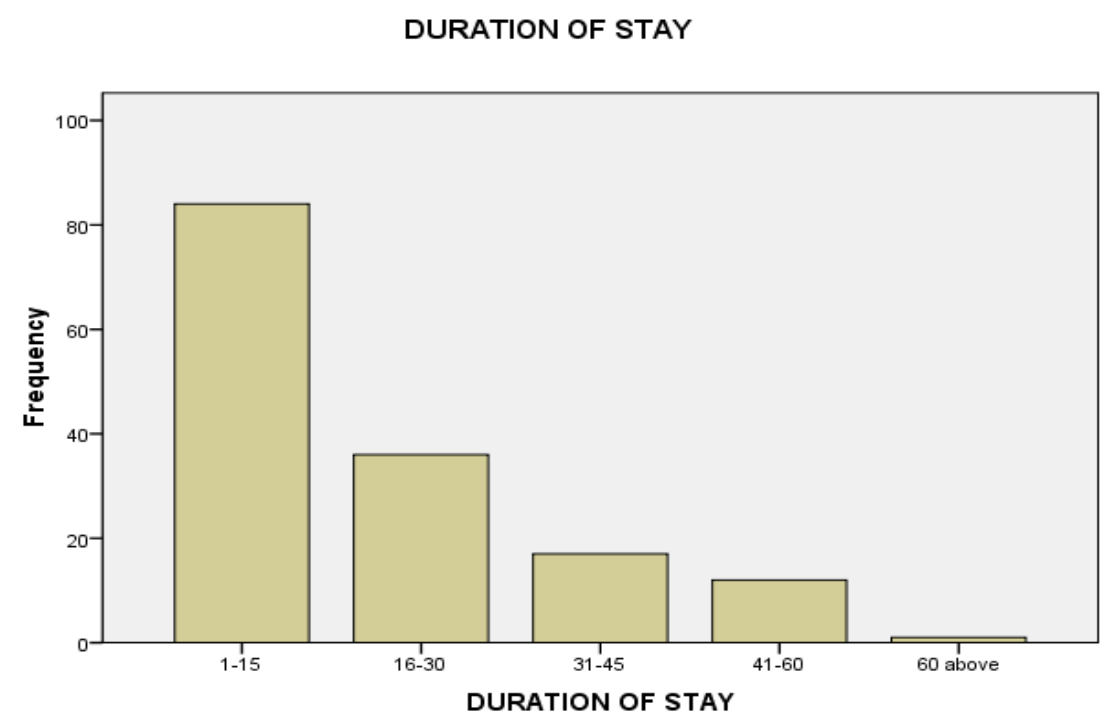

Source: survey 2015

Figure 10: Showing the Duration of staying in this community in the study area

Figure 11: The data clearly show that $56.0 \%$ of the respondent that has to stay in this community represent 1 to 15 years, 24\% of the respondent that has to stay in this community represents 16 to 30 years, $11.3 \%$ of the respondent that has to stay in this community represent 31 to 45 years, $8.0 \%$ of the respondent that has to stay in this community represent 46 to 60 years and $7.0 \%$ of the respondent that has to stay in this community represent 61 year above. 


\section{Status in the community}

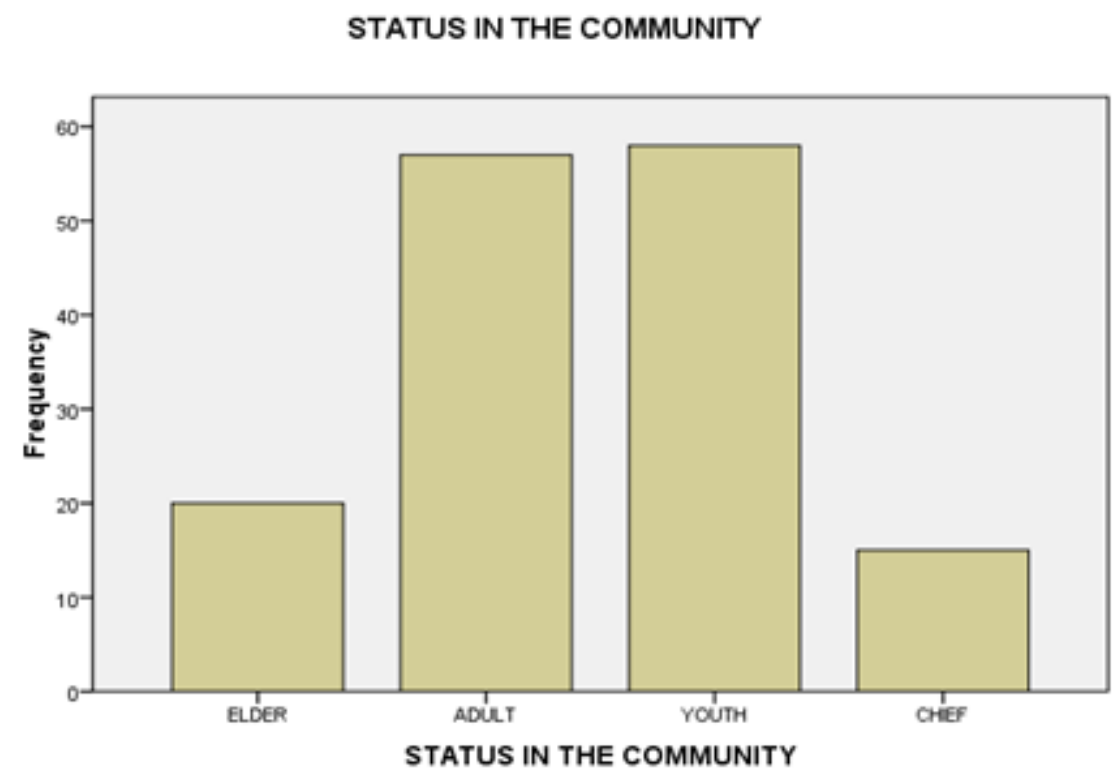

Source: survey 2015

Figure 11: Showing the Status of household head in the study area

Figure 11: The data clearly show that $13.3 .0 \%$ of the respondent are elders that harvest fuelwood in the study area, 38\% of the respondent are Adult that harvest fuelwood in the study area, 38\% of the respondent are also youth that harvest fuelwood in the study area, $10 \%$ of the respondent are chiefs that harvest fuelwood in the study area

The extent of fuelwood harvesting in the study area 
Reason for harvesting fuelwood for firewood

REASONS FOR HARVESTING FUELWOOD-FIRE WOOD

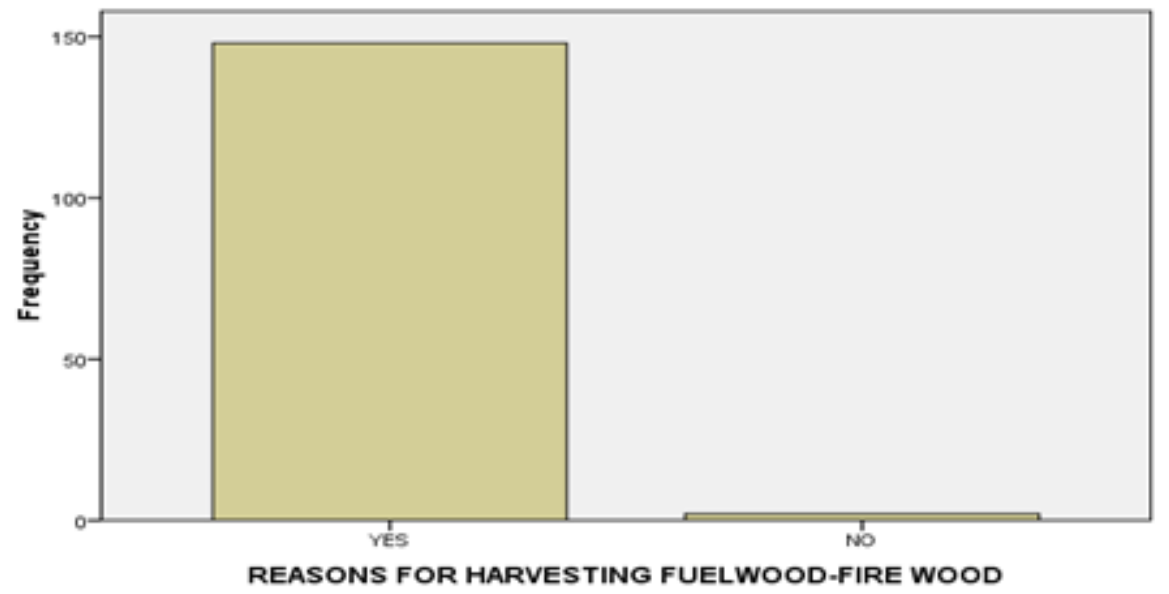

Source: Survey 2015

Figure 12: Showing the reason for harvesting fuelwood for firewood in the study area

Figure 12: show that $98.7 .0 \%$ of the respondent interviewed say Yes they harvest fuelwood for firewood in the study area and $1.3 \%$ of the respondent interviewed say No they do not harvest fuelwood for firewood in the study area.

Reason for harvesting fuelwood for charcoal

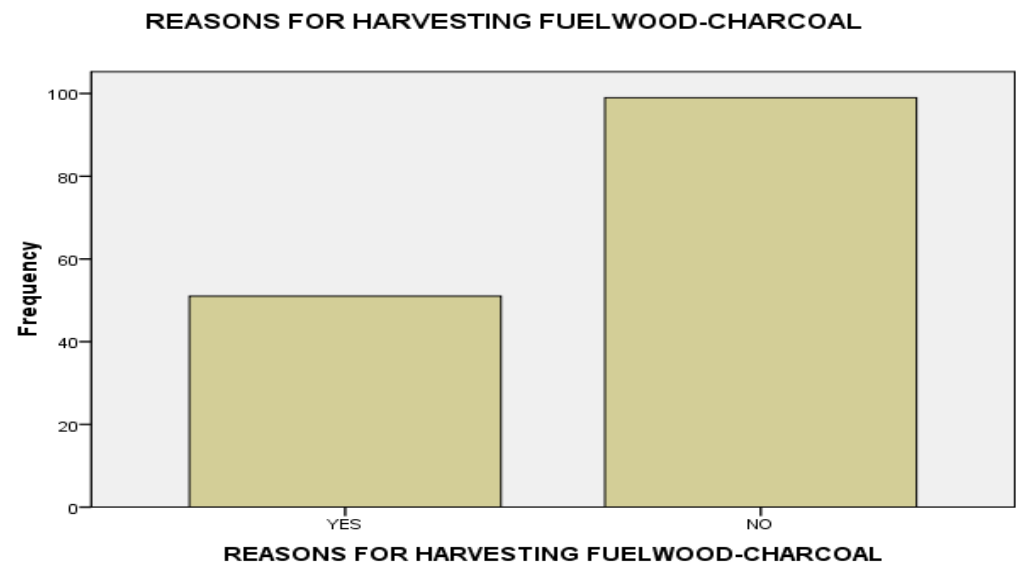

Source: Survey 2015

Figure 13: Showing the reason for harvesting fuelwood for charcoal in the study area 
Figure 13: show that $34.0 .0 \%$ of the respondent interviewed say Yes they harvest fuelwood for charcoal in the study area and $66.0 \%$ of the respondent interviewed say No they do not harvest fuelwood for firewood in the study area.

Reason for harvesting fuelwood for timber

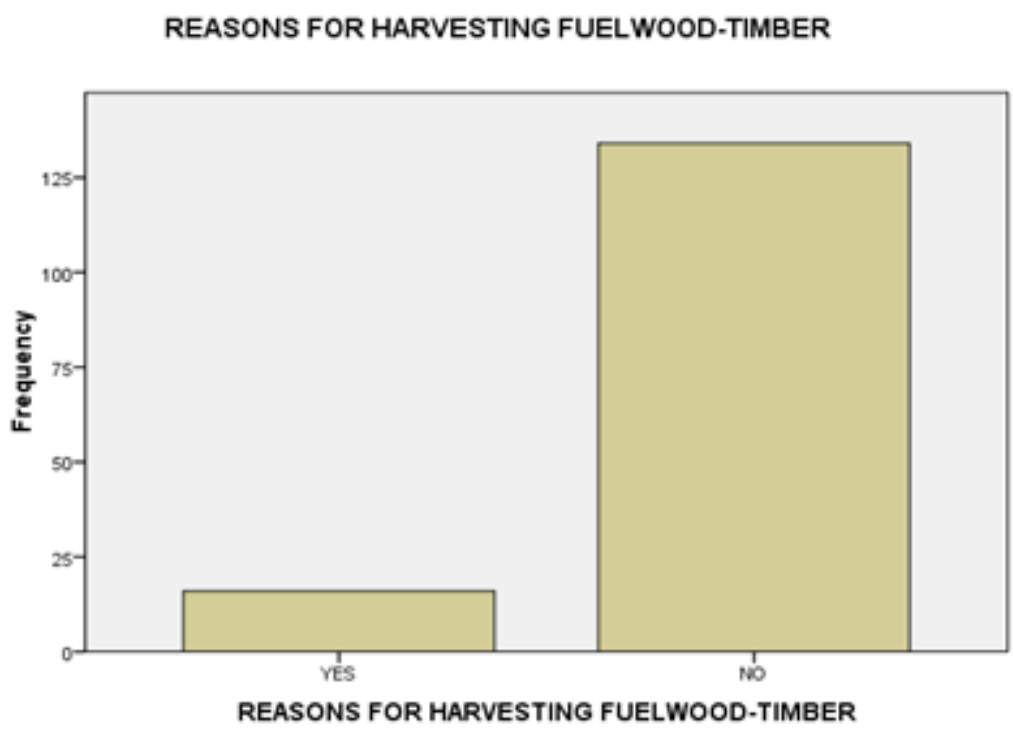

Source: Survey 2015

Figure 14: Showing the reason for harvesting fuelwood for timber in the study area

Figure 14: shows that $10.7 \%$ of the respondent interviewed say Yes they harvest fuelwood for timber in the study area and $89.3 \%$ of the respondent interviewed say No they do not harvest fuelwood for timber in the study area. 


\section{Reason for harvesting fuelwood for pole}

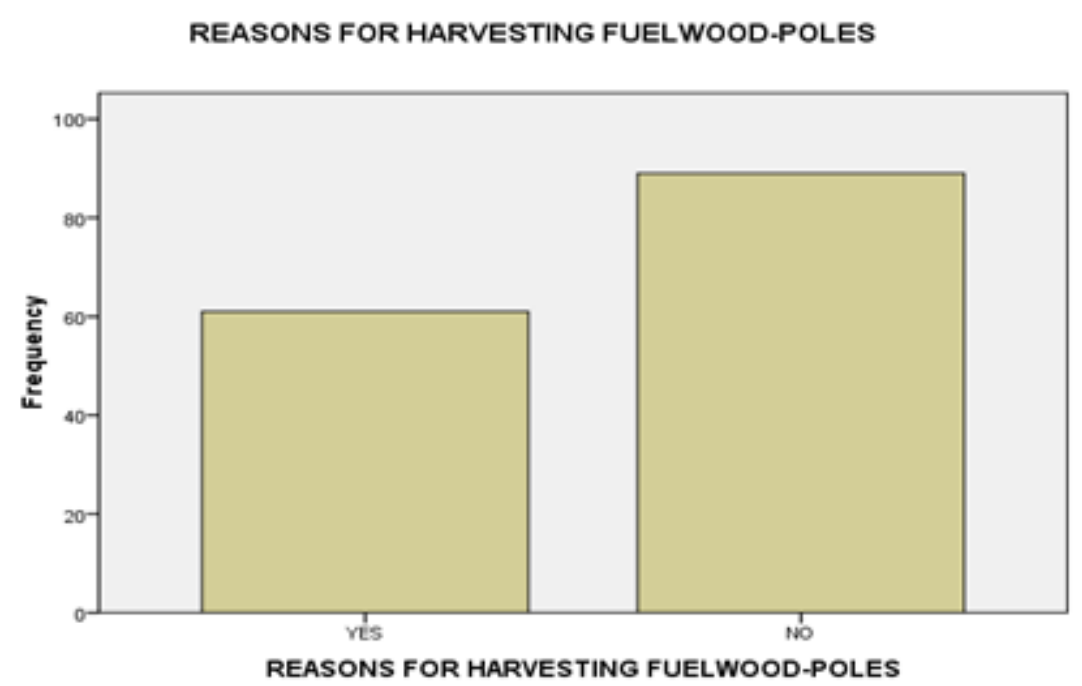

Source: Survey 2015

Figure 15: Showing the reason for harvesting fuelwood for poles in the study area

Figure 15: shows that $40.7 \%$ of the respondent interviewed say yes they harvest fuelwood for poles in the study area and 59.3\% of the respondents interviewed say No they do not harvest fuelwood for poles in the study area.

Reason for harvesting fuelwood for other (specify)

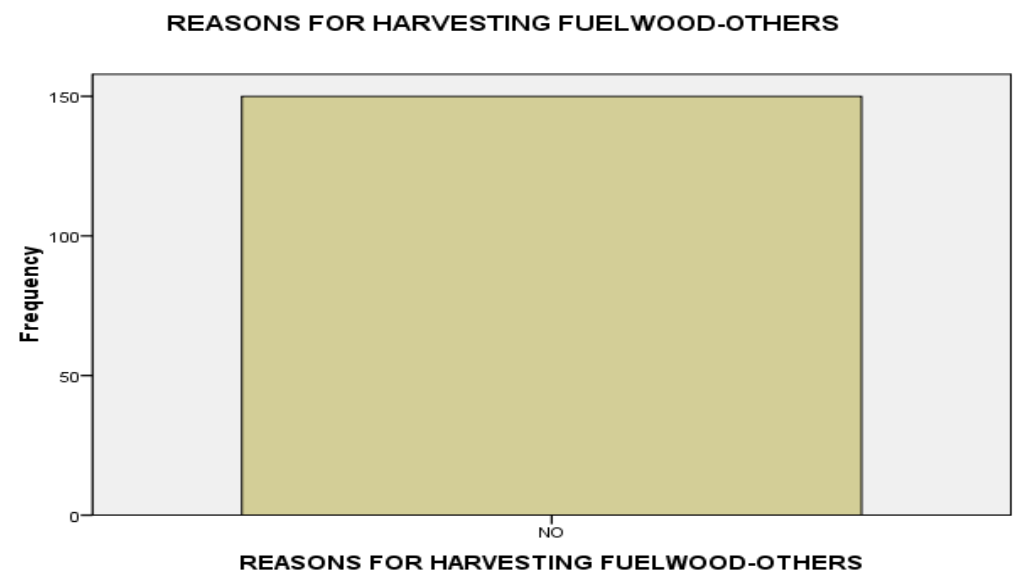

Source: Survey 2015

Figure 16: Showing the reason for harvesting fuelwood for other (specify) in the study area 
Figure 16: shows that $100.0 \%$ of the respondent interviewed says no they do not have any other reason for harvesting fuelwood in the study area.

Why do you harvest for sale only

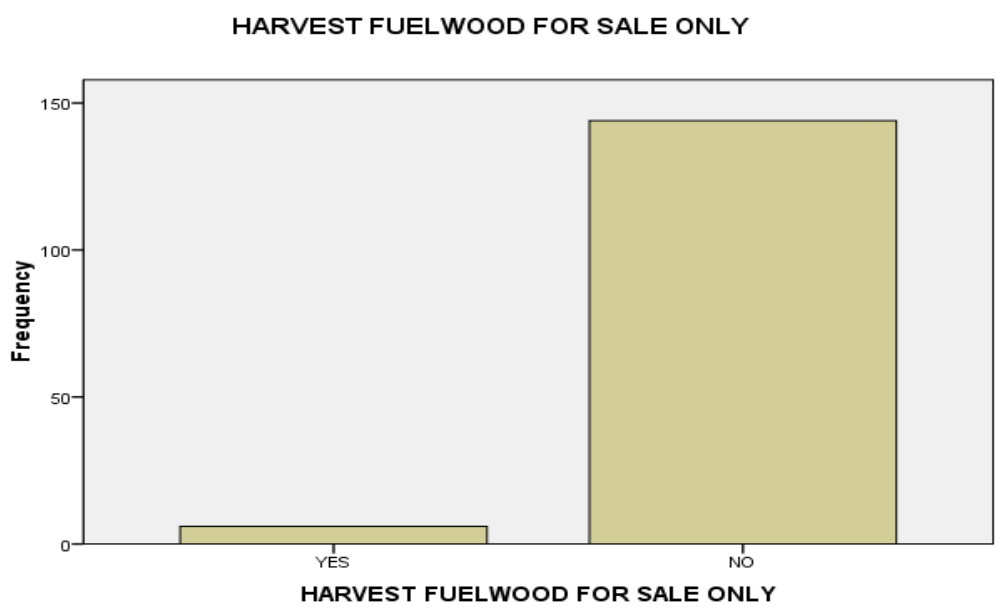

Source: Survey 2015

Figure 17: Showing why they harvesting fuelwood for sale only in the study area

Figure 17: show that $4.0 \%$ of the respondent interviewed say yes they harvest fuelwood for sale only in the study area and $96.0 \%$ of the respondents interviewed say No they do not harvest fuelwood for sale only in the study area.

Why do you harvest for domestic use only

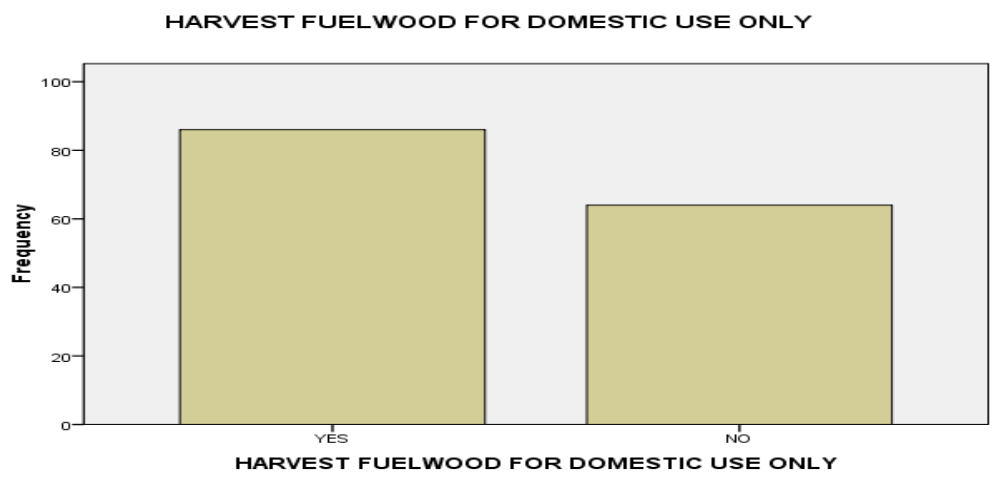

Source: Survey 2015

Figure 18: Showing why they harvesting fuelwood for domestic use only in the study area 
Figure 18: shows that $57.3 \%$ of the respondent interviewed say yes they harvest fuelwood for domestic use only in the study area and $42.7 \%$ of the respondents interviewed say No they do not harvest fuelwood for domestic use only in the study area.

\section{Why do you harvest for both use only}

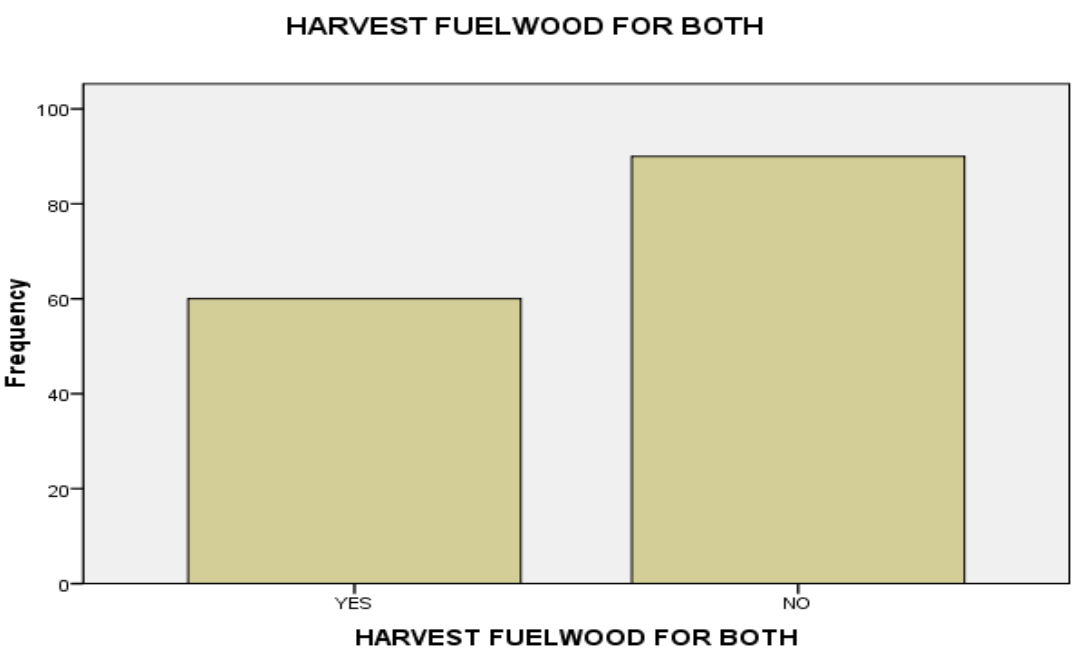

Source: Survey 2015

Figure 19: Showing why they harvesting fuelwood for both (sale and domestic use only) in the study area

Figure 19: shows that $40.0 \%$ of the respondent interviewed say yes they harvest fuelwood for sale and domestic use only in the study area and $60.0 \%$ of the respondents interviewed say No they do not harvest fuelwood for sale and domestic use only in the study area. 


\section{How long have you been engaged in fuelwood harvesting?}

\section{HOW LONG HAVE YOU BEEN ENGAGED IN FUELWOOD HARVESTING}

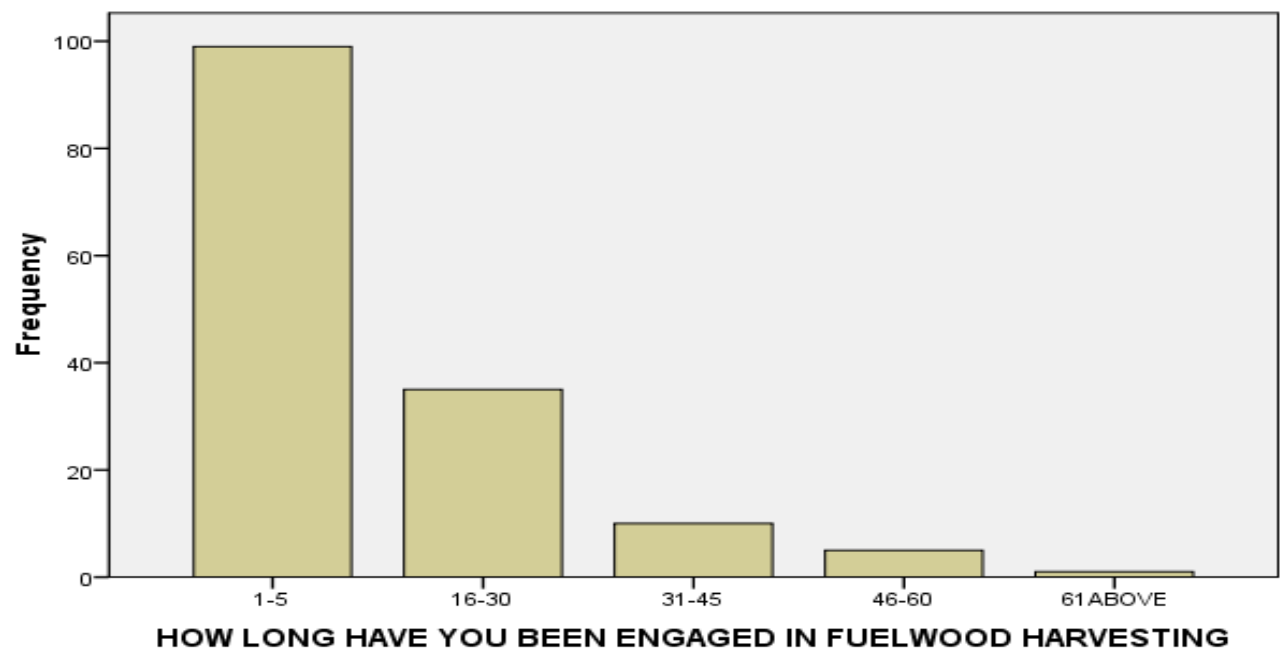

Source: Survey 2015

Figure 20: Showing how long have you been engaged in fuelwood harvesting in the study area

Figure 20: The data clearly show that $66.0 \%$ of the respondent that have engaged in fuelwood harvesting represents 1 to 15 years, $23.3 \%$ of the respondent that have engaged in fuelwood harvesting represents 16 to 30 years, $6.7 \%$ of the respondent that have engaged in fuelwood harvesting represents 31 to 45 years, $3.3 \%$ of the respondent that have to engage in fuelwood harvesting represent- 46 to 60 years and $7.0 \%$ of the respondent that have engaged in fuelwood harvesting represent 61 year. 


\section{How often do you harvest fuelwood per week for firewood?}

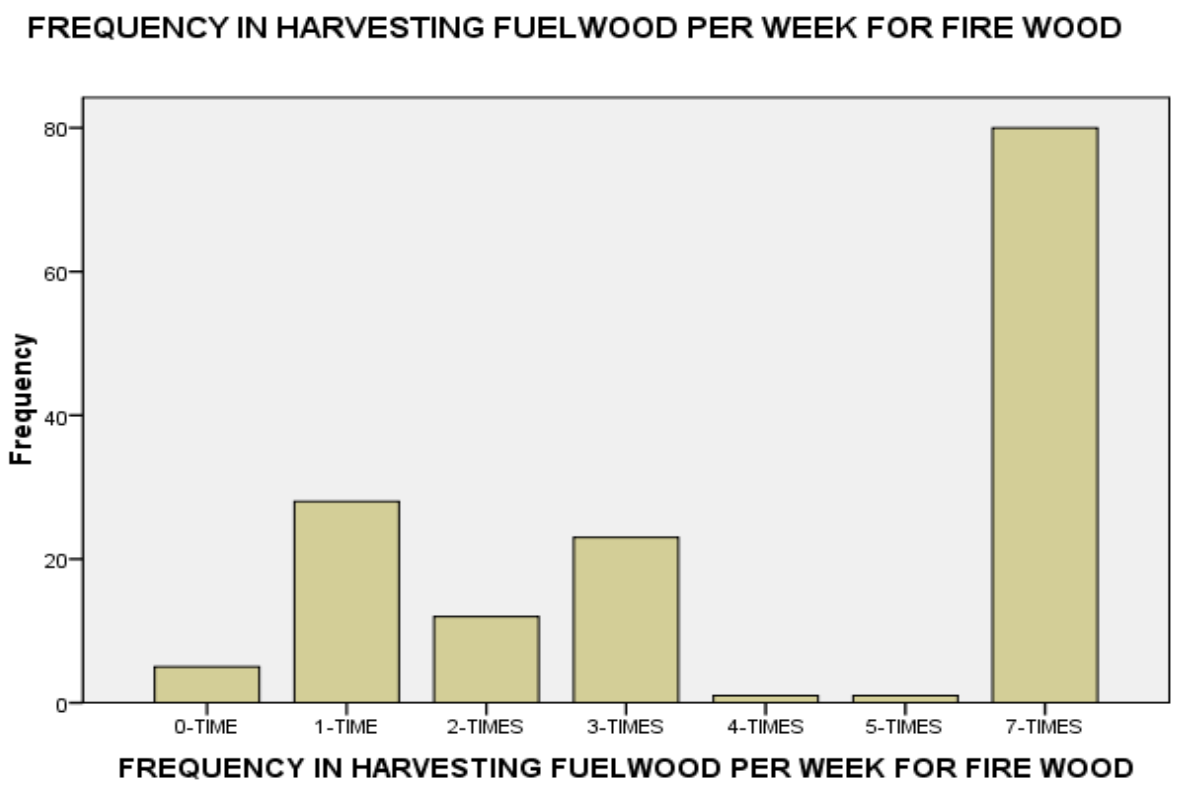

Source: Survey 2015

Figure 21: Showing how often you harvest fuelwood per week for firewood in the study area

Figure 21: The data clearly show that $53.3 \%$ of the respondent often harvest fuelwood per week for firewood represent 7 times, $18.7 \%$ of the respondent often harvest fuelwood per week for firewood represent 1 time, $8.0 \%$ of the respondent often harvest fuelwood per week for firewood represent 2 times, $15.3 \%$ of the respondent that have to engage in fuelwood harvesting for firewood represent 3 times, $7 \%$ of the respondent often harvest fuelwood per week for firewood represent 4 times, $7 \%$ of the respondent often harvest fuelwood per week for firewood represent 5 times and 3.3\% of the respondent often harvest fuelwood per week for firewood represent 0 times. 


\section{How often do you harvest fuelwood per week for timber?}

FREQUENCY IN HARVESTING FUELWOOD PER WEEK FOR TIMBER

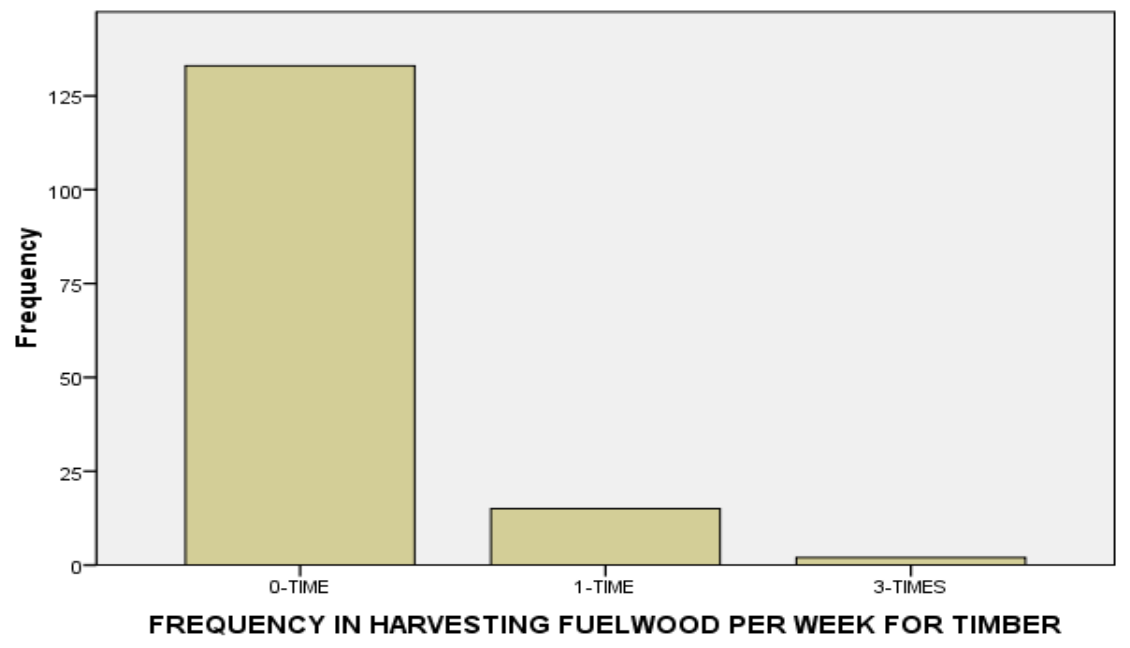

Source: Survey 2015

Figure 22: Showing how often you harvest fuelwood per week for timber in the study area

Figure 22: The data clearly show that $88.7 \%$ of the respondent often harvest fuelwood per week for timber represent 0 times, $10.0 \%$ of the respondent often harvest fuelwood per week for timber represent 1 time and $1.3 \%$ of the respondent often harvest fuelwood per week for timber represent 3 times. 


\section{How often do you harvest fuelwood per week for charcoal?}

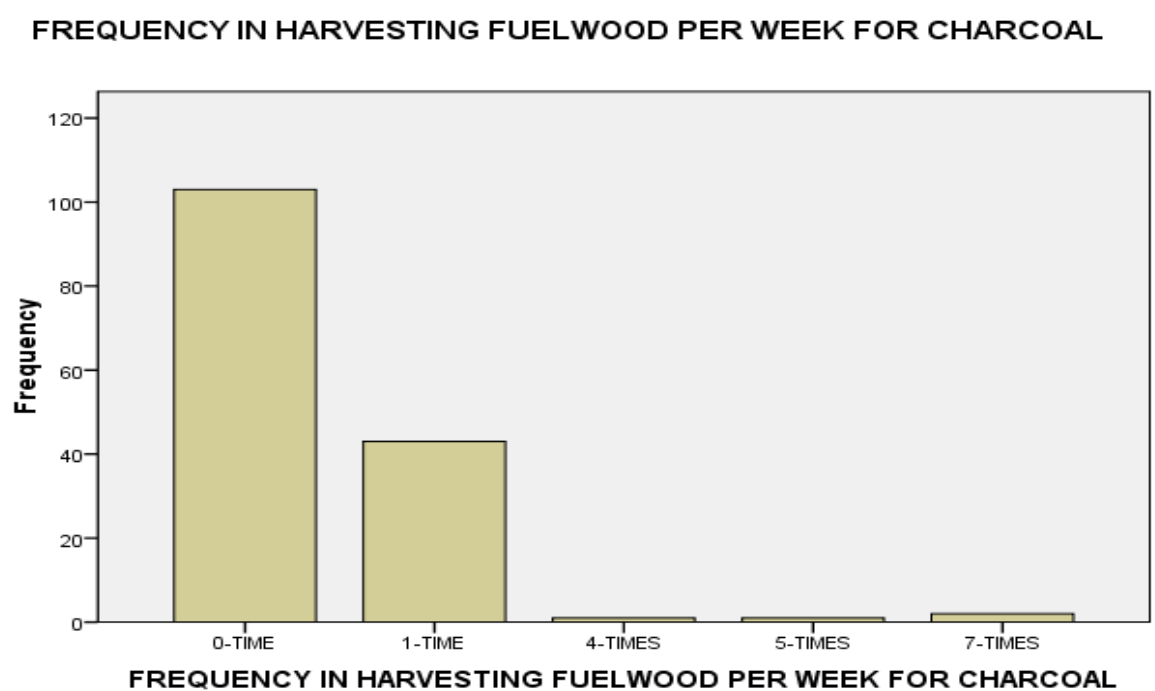

Source: Survey 2015

Figure 23: Showing how often you harvest fuelwood per week for timber in the study area

Figure 23: The data clearly show that $68.7 \%$ of the respondent often harvest fuelwood per week for charcoal represent 0 times, $28.0 \%$ of the respondent often harvest fuelwood per week for charcoal represent 1 time and $7 \%$ of the respondent often harvest fuelwood per week for timber represent 4 times. 7\% \% of the respondent often harvests fuelwood per week for charcoal represent 5 times and $1.3 \% \%$ of the respondent often harvests fuelwood per week for timber represent 7 times. 


\section{How often do you harvest fuelwood per week for pole?}

FREQUENCY IN HARVESTING FUELWOOD PER WEEK FOR POLE

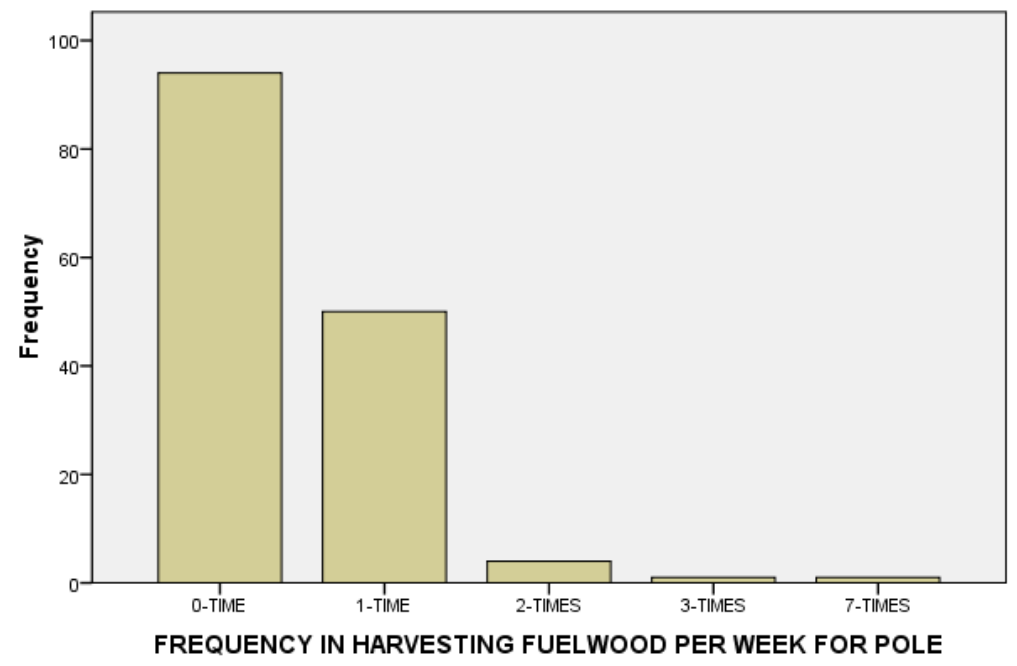

Source: Survey 2015

Figure 24: Showing how often you harvest fuelwood per week for pole in the study area

Figure 24: The data clearly show that $63.7 \%$ of the respondent often harvest fuelwood per week for pole represent 0 times, $33.3 \%$ of the respondent often harvest fuelwood per week for pole represent 1 time, $2.7 \%$ of the respondent often harvest fuelwood per week for pole represent 2 times, $7 \%$ of the respondent that have engaged in fuelwood harvesting per week for pole represent 3 times and 7\% of the respondent often harvest fuelwood per week for pole represent 7 times. 
The average quantity of fuelwood harvest in one go for firewood

AVERAGE QUANTITY OF FUELWOOD HARVESTED-FIRE WOOD

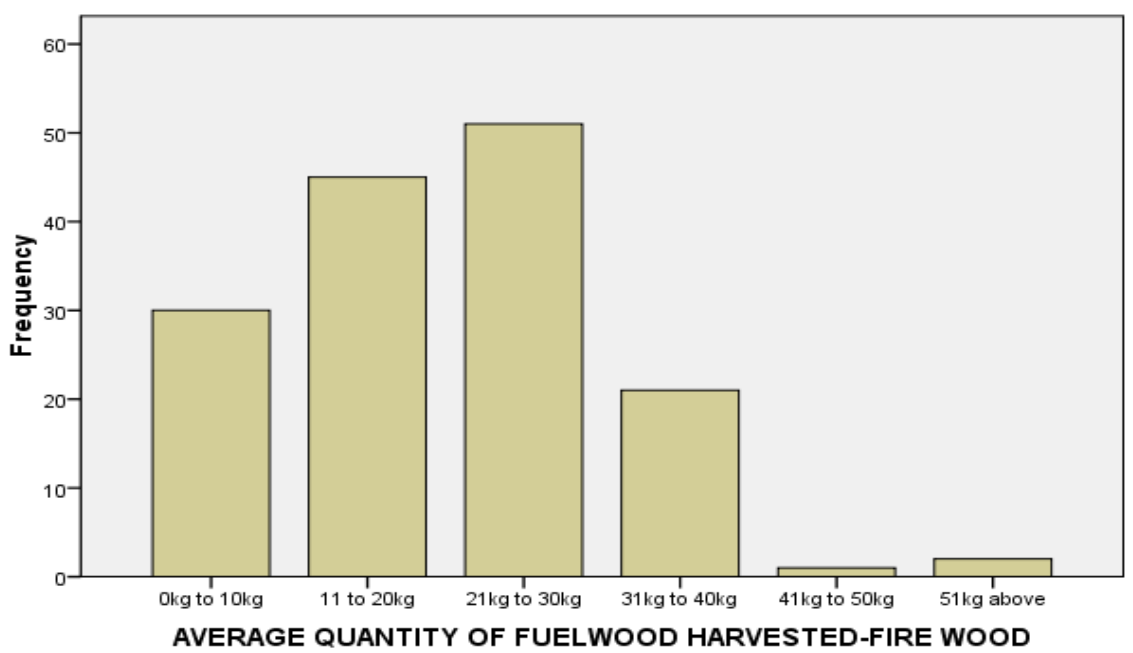

Source: survey 2015

Figure 25: Showing the Average quantities of fuelwood harvest in one go in the study area

Figure 25: The data clearly show that $20.0 \%$ of the respondent average quantities of fuelwood harvest in one go is less than equal to $0 \mathrm{~kg}$ to $10 \mathrm{~kg}$. $30.0 \%$ of the respondent average quantity of fuelwood harvest in one go is less than equal to $11 \mathrm{~kg}$ to $20 \mathrm{~kg}, 34 \%$ average quantity of fuelwood harvest in one go is less than equal to $21 \mathrm{~kg}$ to $30 \mathrm{~kg}, 14.0 \%$ average quantity of fuelwood harvest in one go is less than equal to $31 \mathrm{~kg}$ to $40 \mathrm{~kg}, 7 \%$ average quantity of fuelwood harvest in one go is less than equal to $41 \mathrm{~kg}$ to $50 \mathrm{~kg}$ and $1.3 \%$ average quantity of fuelwood harvest in one go is less than equal to $51 \mathrm{~kg}$ above 
The average quantity of fuelwood harvest in one go for timber

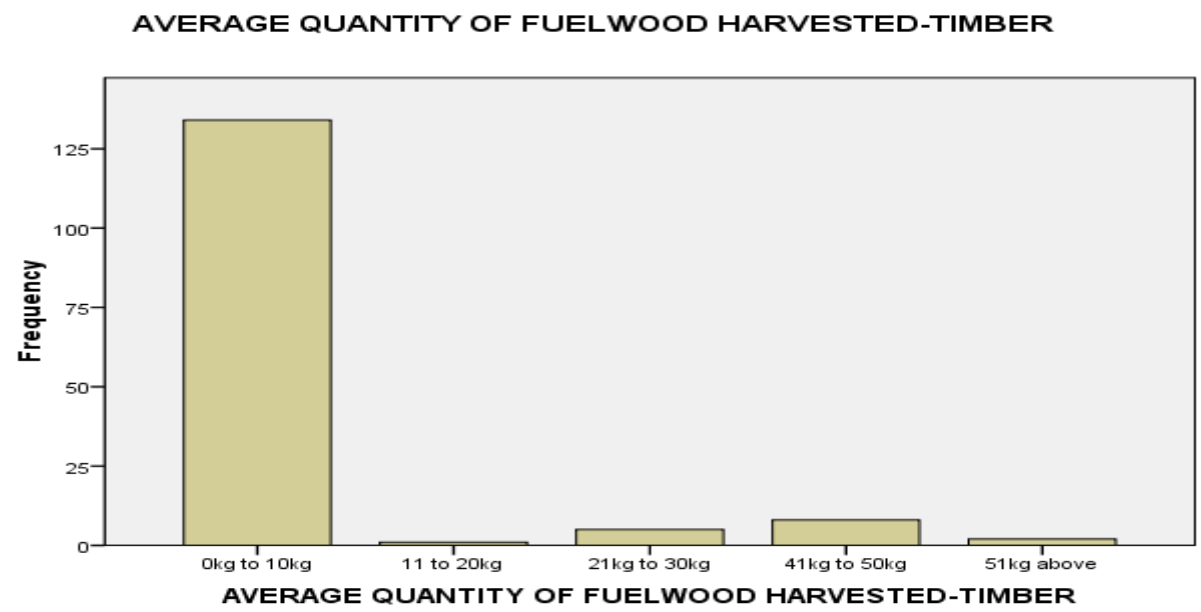

Source: survey 2015

Figure 26: Showing the Average quantities of timber harvest in one go in the study area

Figure 26: The data clearly show that $89.3 \%$ of the respondent average quantities of timber harvest in one go is less than equal to $0 \mathrm{~kg}$ to $10 \mathrm{~kg}, 7 \%$ of the respondent average quantity of timber harvest in one go is less than equal to $11 \mathrm{~kg}$ to $20 \mathrm{~kg}, 3.3 \%$ average quantity of timber harvest in one go is less than equal to $21 \mathrm{~kg}$ to $30 \mathrm{~kg}, 5.1 \%$ average quantity of timber harvest in one go is less than equal to $41 \mathrm{~kg}$ to $50 \mathrm{~kg}$ and $1.3 \%$ quantity of fuelwood harvest in one go is less than equal to $51 \mathrm{~kg}$ above. 
The average quantity of fuelwood harvest in one go for Charcoal

AVERAGE QUANTITY OF FUELWOOD HARVESTED-CHARCOAL

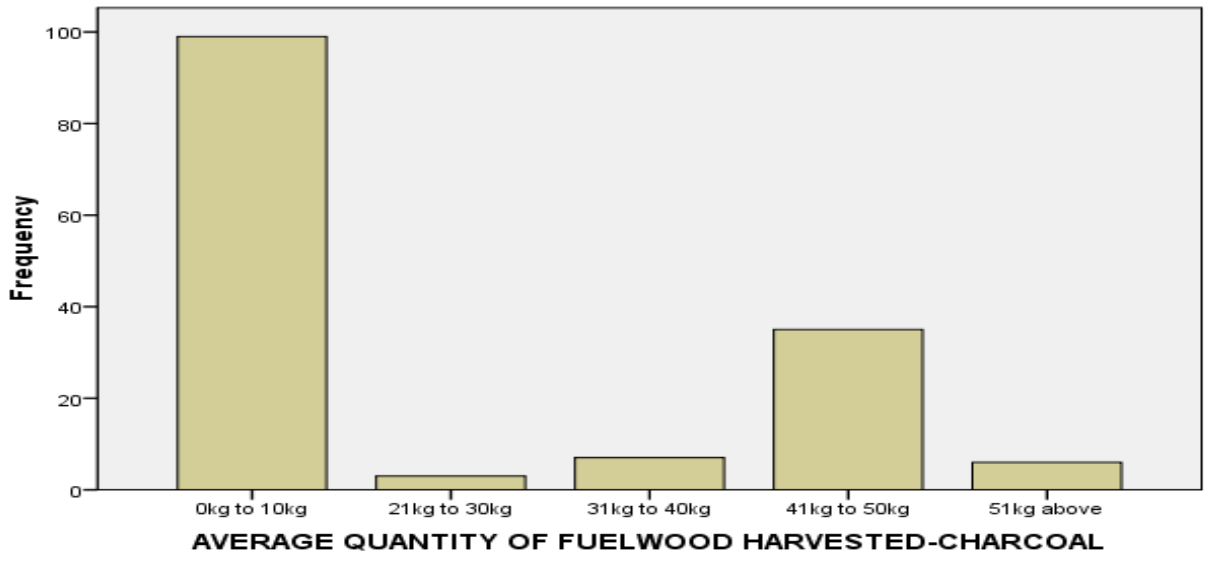

Source: survey 2015

Figure 27: Showing the Average quantities of charcoal harvest in one go in the study area

Figure 27: The data clearly show that $66.0 \%$ of the respondent average quantities of timber harvest in one go is less than equal to $0 \mathrm{~kg}$ to $10 \mathrm{~kg}, 4.7 \%$ average quantity of timber harvest in one go is less than equal to $21 \mathrm{~kg}$ to $30 \mathrm{~kg}, 23.3 \%$ average quantity of timber harvest in one go is less than equal to $41 \mathrm{~kg}$ to $50 \mathrm{~kg}$ and $4.0 \%$ quantity of fuelwood harvest in one go is less than equal to $51 \mathrm{~kg}$ above.

The average quantity of fuelwood harvest in one go for pole

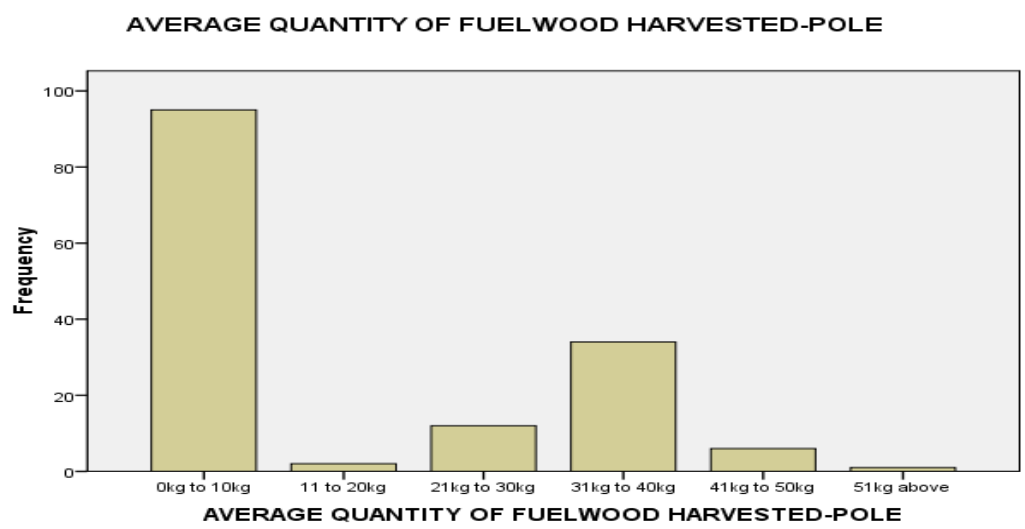

Source: survey 2015

Figure 28: Showing the Average quantities of pole harvest in one go in the study area 
Figure 28: The data clearly show that $63.3 \%$ of the respondent average quantities of pole harvest in one go is less than equal to $0 \mathrm{~kg}$ to $10 \mathrm{~kg}$. $1.3 \%$ of the respondent average quantity of pole harvest in one go is less than equal to $11 \mathrm{~kg}$ to $20 \mathrm{~kg}, 8.0 \%$ average quantity of pole harvest in one go is less than equal to $21 \mathrm{~kg}$ to $30 \mathrm{~kg}, 22.0 \%$ average quantity of pole harvest in one go is less than equal to $31 \mathrm{~kg}$ to $40 \mathrm{~kg}, 4.0 \%$ average quantity of fuelwood harvest in one go is less than equal to $41 \mathrm{~kg}$ to $50 \mathrm{~kg}$ and $7 \%$ average quantity of fuelwood harvest in one go is less than equal to $51 \mathrm{~kg}$ above.

\subsubsection{What is the cost per unit of fuelwood harvested for firewood?}

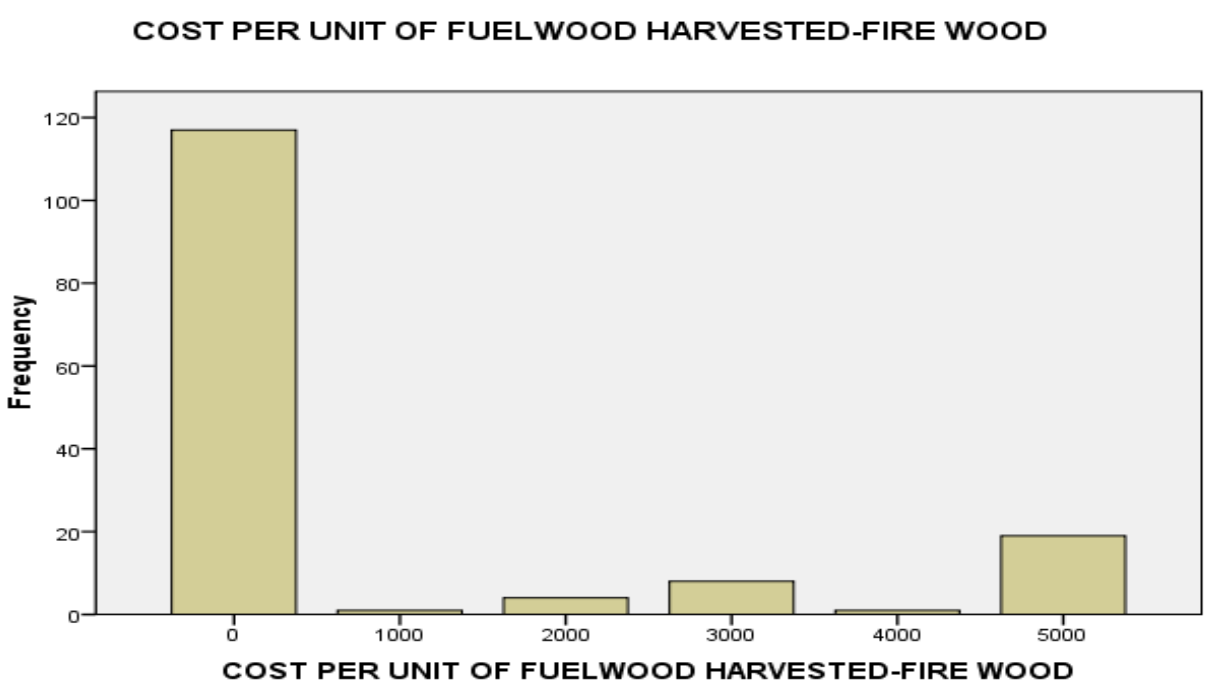

Source: Survey 2015

Figure 29: showing the cost per unit of fuelwood harvested for firewood

Figure 29: out of the percentage of the household head that belong in the study area $7 \%$ of them sell fuelwood as firewood at 1000 Leone, $2.7 \%$ at 2000 Leone,5.3\% at 3000 Leone, $7 \%$ at 4000 Leone, $12.7 \%$ at 5000 Leone and $78.0 \%$ of them do not harvest fuelwood for sell.

What is the cost per unit of fuelwood harvested for timber? 


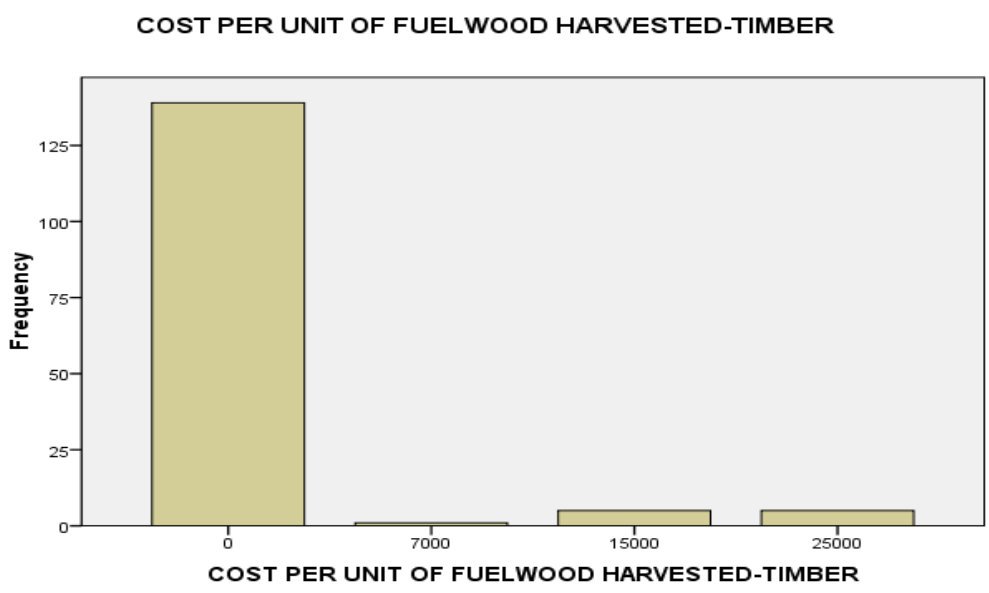

Source: Survey 2015

Figure 30: showing the cost per unit of fuelwood harvested for timber

Figure 30: out of the percentage of the household head that belongs in the study area $7 \%$ of them sell fuelwood as timber at 7000 Leone,3.3\% at 15000 Leone,3.3 at 25000 Leone, and $92.7 .0 \%$ of them do not harvest timber for sell.

What is the cost per unit of fuelwood harvested for charcoal?

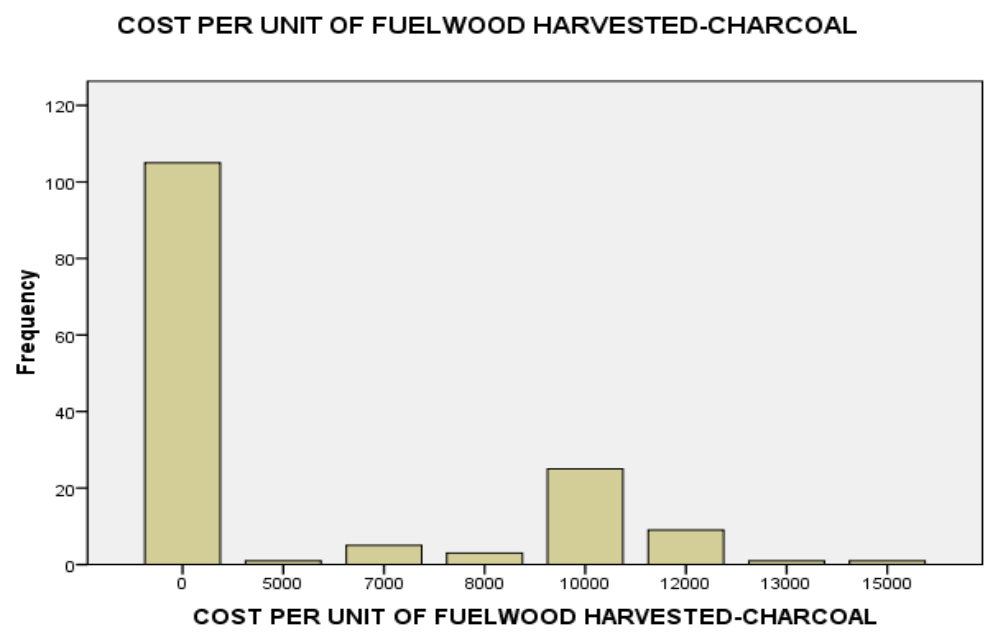

Source: Survey 2015

Figure 31: showing the cost per unit of fuelwood harvested for charcoal 
Figure 31: out of the percentage of the household head that belong in the study area $7 \%$ of them sell fuelwood as firewood at 5000 Leone per bag, 3.3\% at 7000 Leone per bag, $2.0 \%$ at 8000 Leone per bag, $16.7 \%$ at 10000 Leone per bag, $6.0 \%$ at 12000 Leone per bag, $7 \%$ at 13000 Leone per bag,7\% at 15000 Leone per bag and $70.0 \%$ of them do not harvest fuelwood for charcoal for sell.

What is the cost per unit of fuelwood harvested for pole

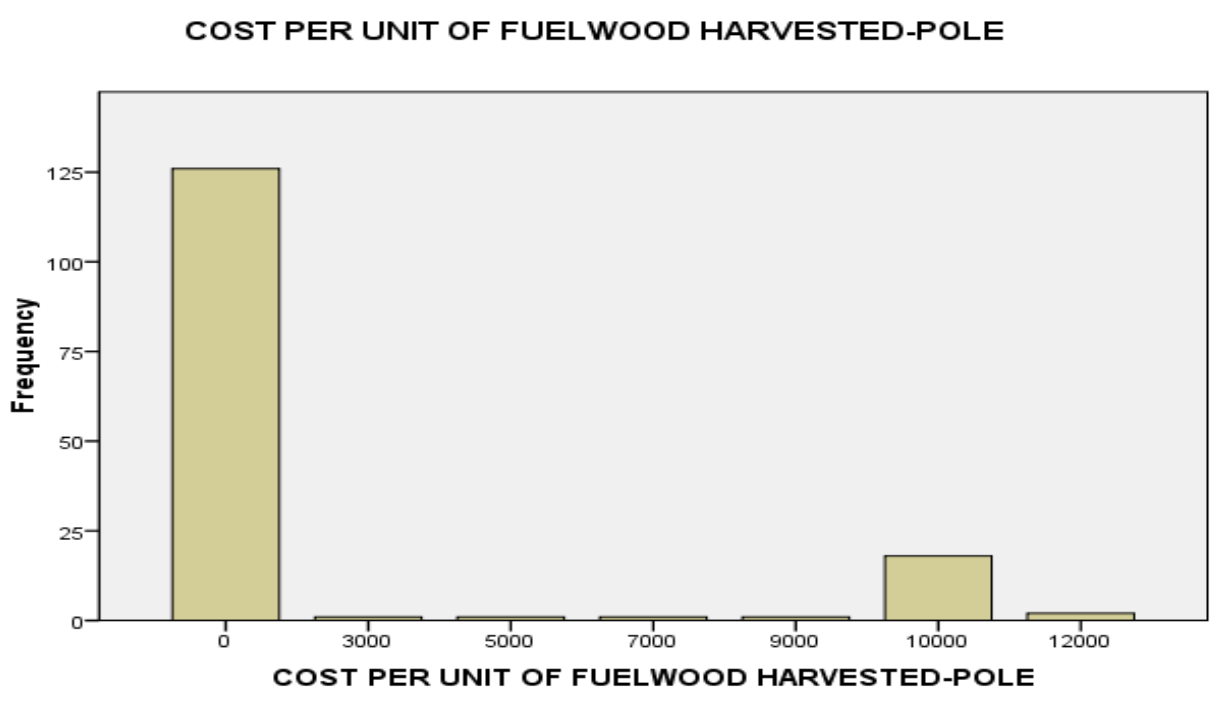

Source: Survey 2015

Figure 32: showing the cost per unit of fuelwood harvested for pole

Figure 32: out of the percentage of the household head that belong in the study area $7 \%$ of them sell fuelwood as a pole at 3000 Leone per bunch, 7\% at 5000 Leone per bunch,7.0\% at 7000 Leone per bunch, $7.0 \%$ at 9000 Leone per bunch, $12.0 \%$ at 10000 Leone per bag and $84.0 \%$ of them do not harvest fuelwood as a pole for sell.

Estimate time spent to travel from your resident to the place you harvested fuel wood when you started the business. 


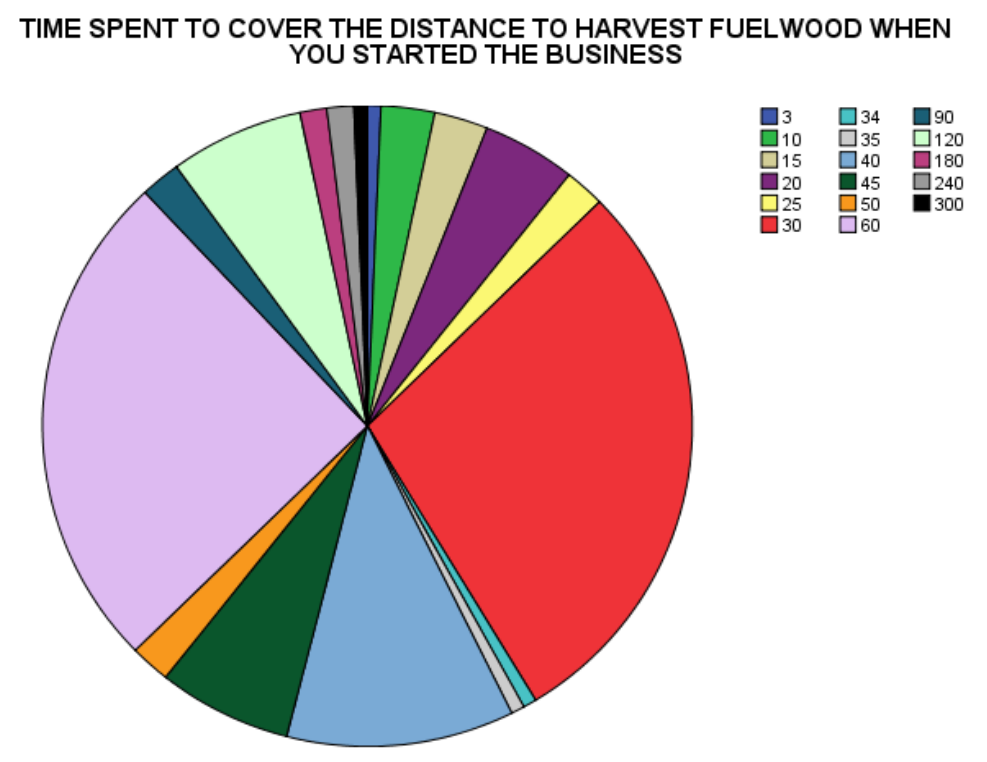

Source: Survey 2015

Figure 33: showing the Estimate time spent to travel from the resident of the respondents' to the place they are harvesting fuelwood when they started the business.

Figure 33: tell us that they spent a total time of 1297 minutes when they started the business to harvest fuelwood.

Estimate time spent now to travel from your resident to the place you harvested fuelwood. 


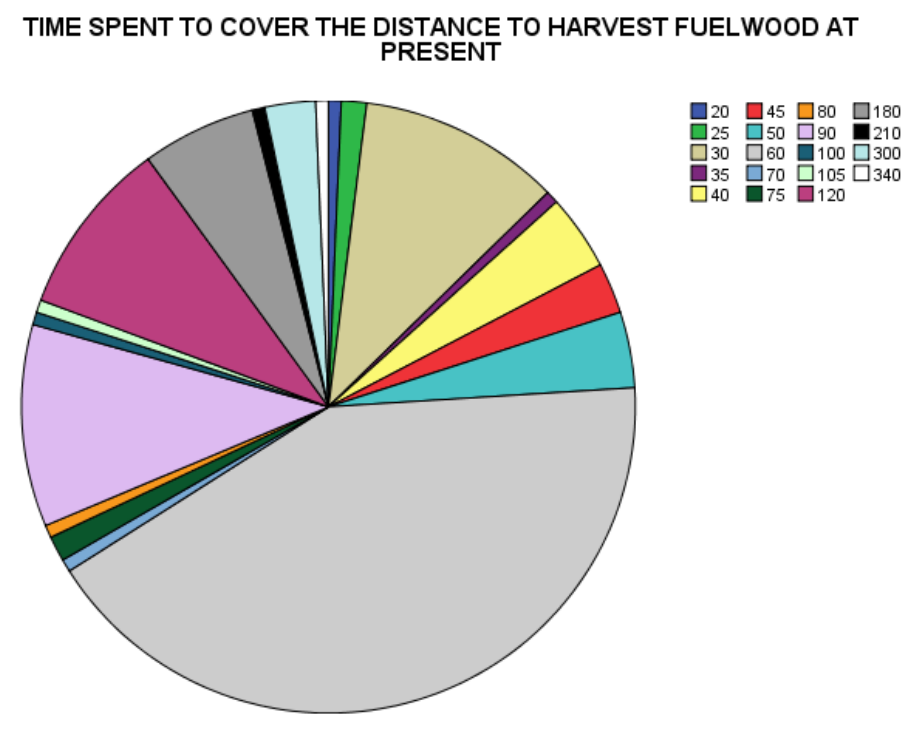

Source: Survey 2015

Figure 34: showing the Estimate time spent now to travel from the resident of the respondents' to the place they are harvesting fuelwood.

Figure 34: tell us that they spent a total time of 1975 minutes now to travel to the place they harvest fuelwood.

Out of the proportion of fuelwood that you harvest estimate the proportion by the use you make of it for firewood for sale. 


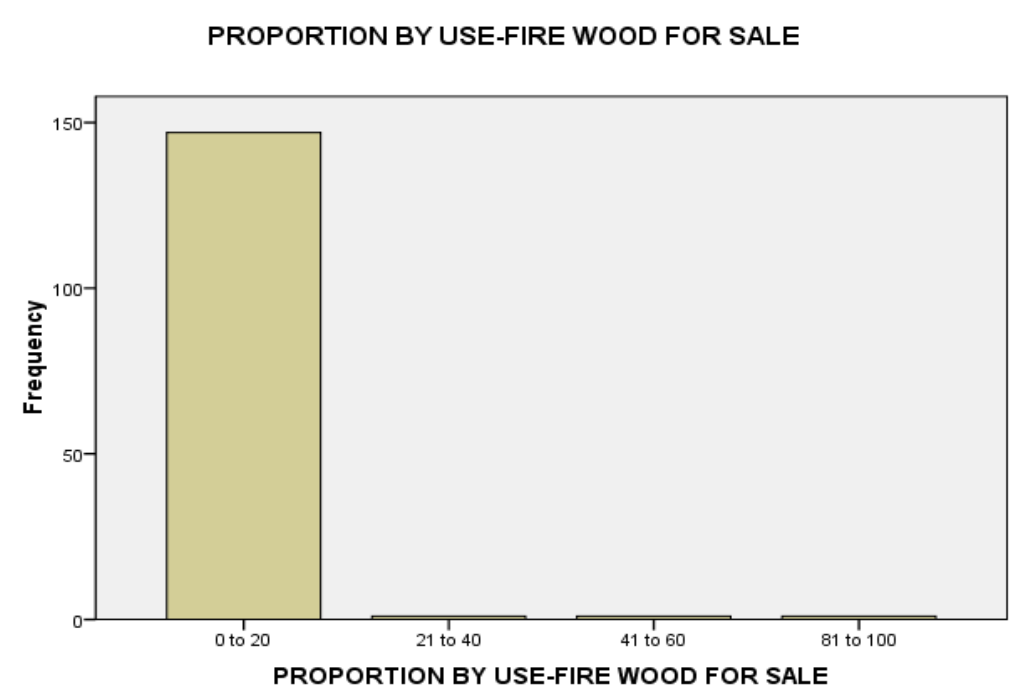

Source: Survey 2015

Figure 35: showing the proportion of fuelwood that they harvest, estimate the proportion by the use you make of it for sale for firewood.

Figure 35: out of the proportion by use $72.7 .0 \%$ of the household head put 0 to 20 bunch for sale for firewood,7\% put 21 to 40 bunch for sale,7\% put 41 to 60 bunch for sale and $7 \%$ put 81 to 100 bunch for sale.

Out of the proportion of fuelwood that you harvest estimate the proportion by the use you make of it for charcoal for sale. 


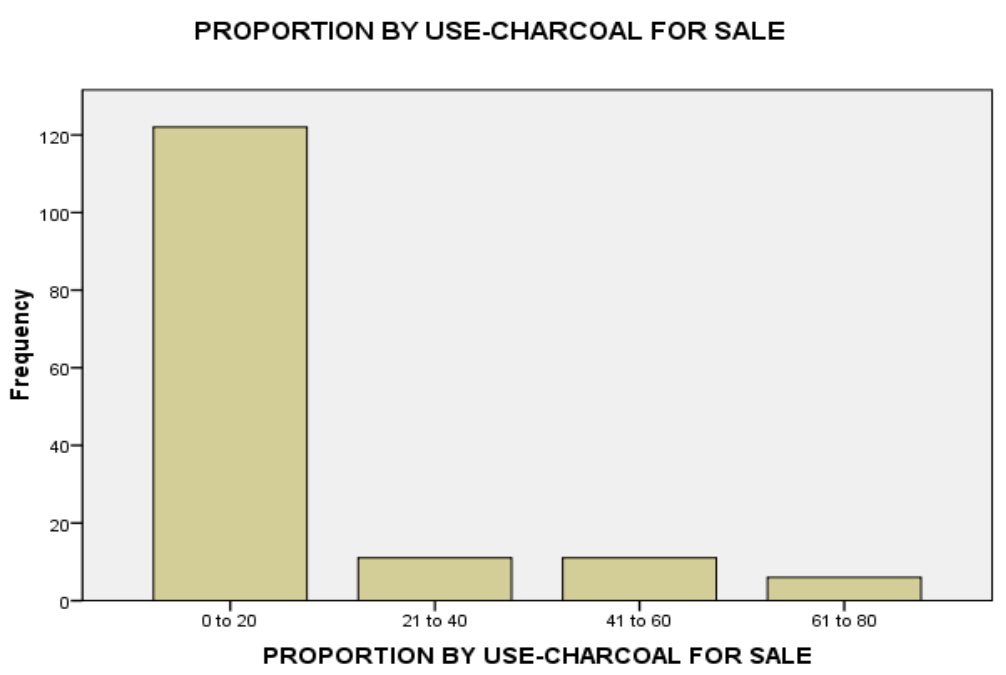

Source: Survey 2015

Figure 36: showing the proportion of fuelwood that they harvest, estimate the proportion by the use you make of it for sale for charcoal.

Figure 36: out of the proportion by using $81.3 \%$ of the household head put 0 to 20 bunches for sale for timber, $7.3 \%$ put 21 to 40 bunches for sale, $7.3 \%$ put 41 to 60 bunches for sale and $4.0 \%$ put 61 to 80 bunches for sale.

Out of the proportion of fuelwood that you harvest estimate the proportion by the use you make of it for timber for sale. 


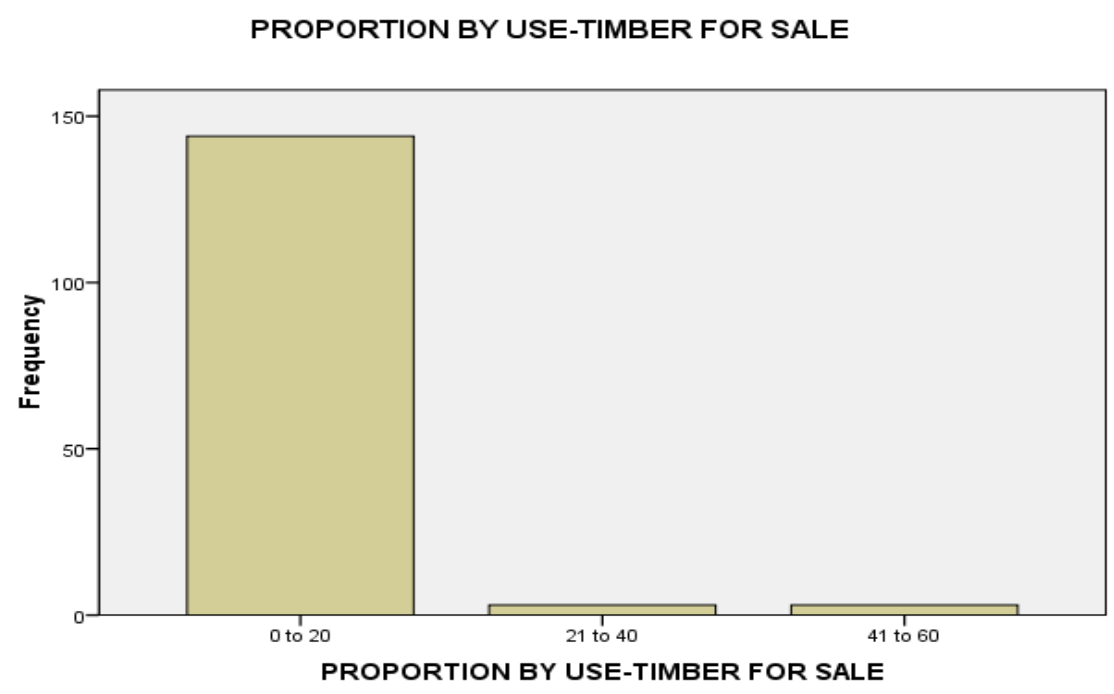

Source: Survey 2015

Figure 37: showing the proportion of fuelwood that they harvest, estimate the proportion by the use you make of it for sale for timber.

Figure 37: out of the proportion by using $96.0 \%$ of the household head put 0 to 20 bunches for sale for timber, $2.0 \%$ put 21 to 40 bunches for sale and $2.0 \%$ put 41 to 60 .

Out of the proportion of fuelwood that you harvest estimate the proportion by the use you make of it for the pole for sale. 
PROPORTION BY USE- POLE FOR SALE

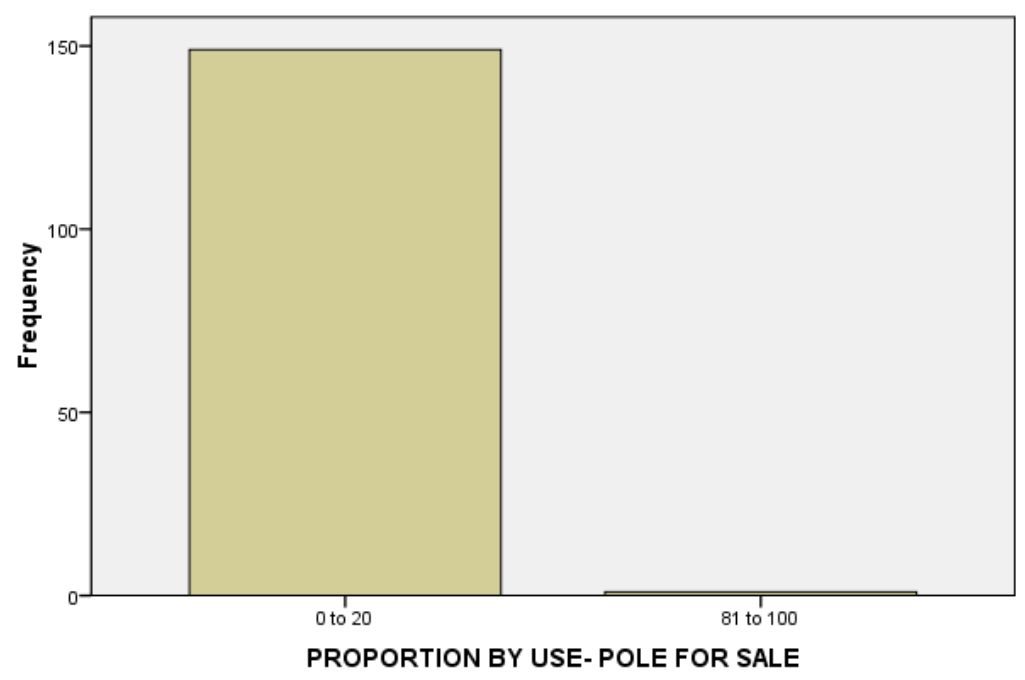

Source: Survey 2015

Figure 38: showing the proportion of fuelwood that they harvest, estimate the proportion by the use you make of it for sale for pole.

Figure 38: out of the proportion by using $99.0 \%$ of the household head put 0 to 20 bunches for sale for pole and $7 \%$ put 81 to 100 bunches for sale.

Out of the proportion of fuelwood that you harvest estimate the proportion by the use you make of it for firewood for household use. 
PROPORTION BY USE-FIRE WOOD FOR HOUSEHOLD

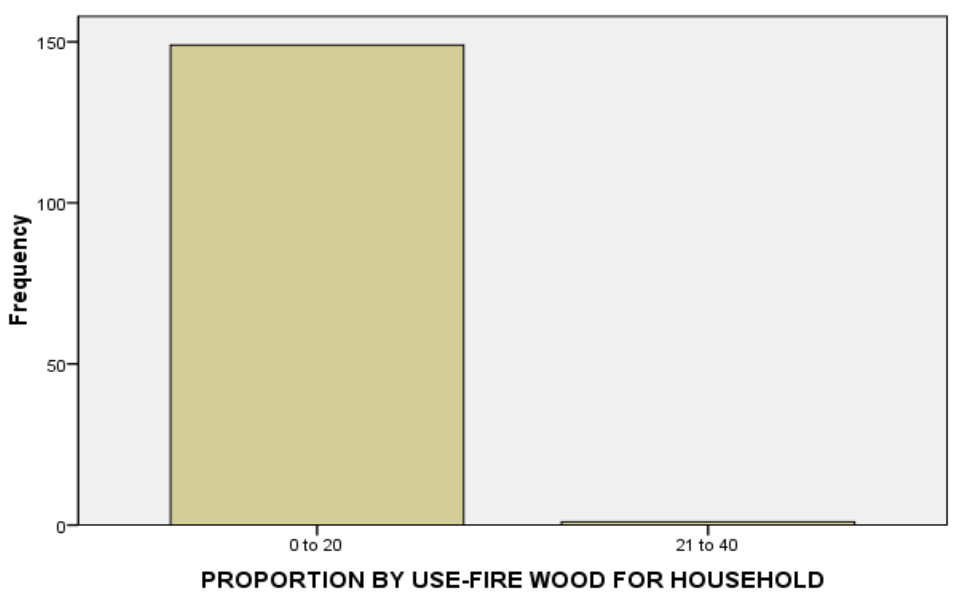

Source: Survey 2015

Figure 39: showing the proportion of fuelwood that they harvest, estimate the proportion by the use you make of it for the household for firewood.

Figure 39: out of the proportion by using $99.3 \%$ of the household head put 0 to 20 bunches for household use as firewood and $7 \%$ put 21 to 40 bunches for household as firewood.

Out of the proportion of fuelwood that you harvest estimate the proportion by the use you make of it for charcoal for household use.

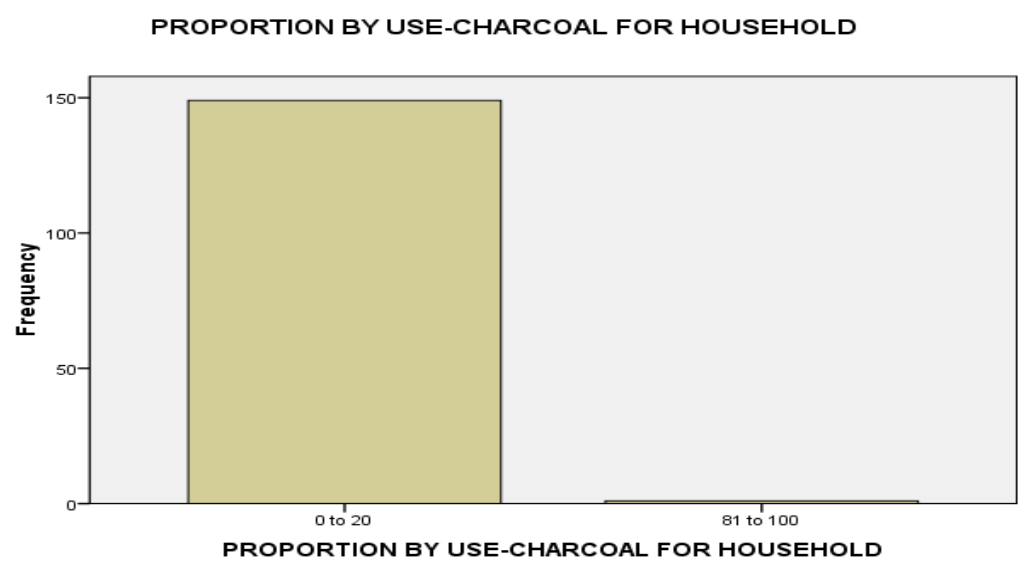

Source: Survey 2015

Figure 40: showing the proportion of fuelwood that they harvest, estimate the proportion by the use you make of it for the household for charcoal. 
Figure 40: out of the proportion by using $99.3 \%$ of the household head put 0 to 20 bunches for household use as charcoal and $7 \%$ put 81 to 100 bunches for household as charcoal.

Out of the proportion of fuelwood that you harvest estimate the proportion by the use you make of it for timber for household use.

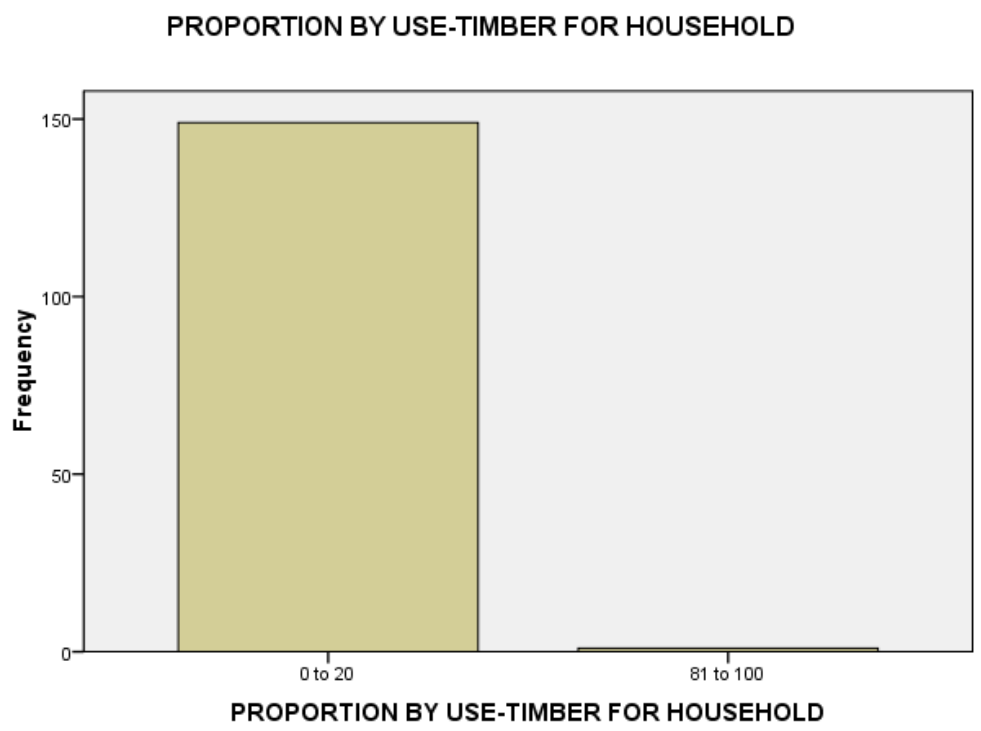

Source: Survey 2015

Figure 41: showing the proportion of fuelwood that they harvest, estimate the proportion by the use you make of it for the household for timber.

Figure 41: out of the proportion by using $99.3 \%$ of the household head put 0 to 20 for household use as timber and $7 \%$ put 81 to 100 bunches for household as timber.

Out of the proportion of fuelwood that you harvest estimate the proportion by the use you make of it for the pole for household use. 


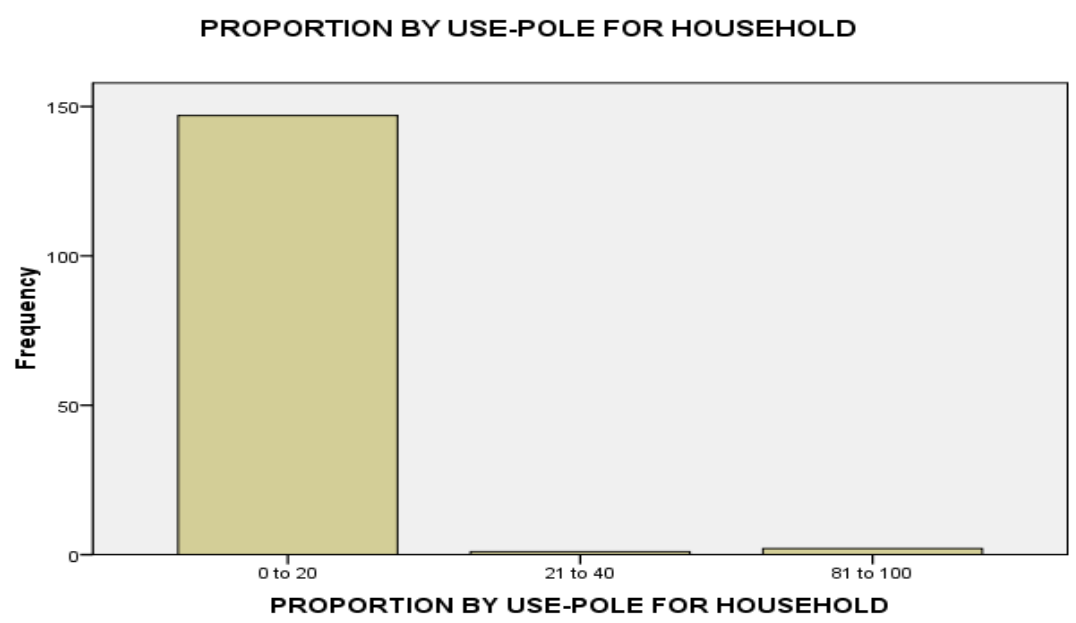

Source: Survey 2015

Figure 42: showing the proportion of fuelwood that they harvest, estimate the proportion by the use you make of it for the household for charcoal.

Figure 42: out of the proportion by using $98.0 \%$ of the household head put 0 to 20 bunches for household use as a pole, $7 \%$ put 21 to 40 bunches for household as a pole and $1.3 \%$ put 81 to 100 bunches.

Out of the proportion of fuelwood that you harvest estimate the proportion by the use you make of it for firewood for project return.

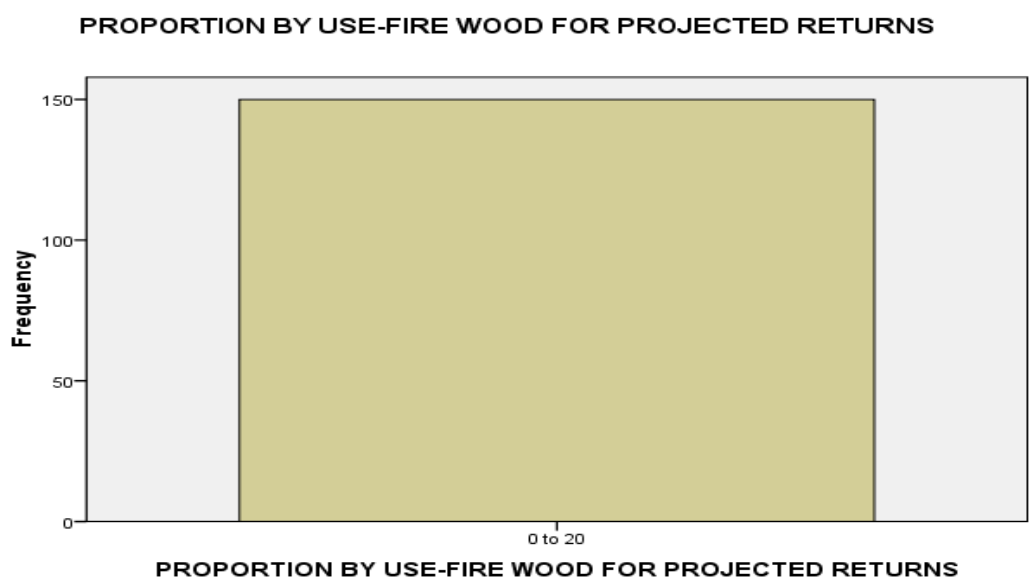

Source: Survey 2015

Figure 43: showing the proportion of fuelwood that they harvest, estimate the proportion by the use you make of it for firewood for project return. 
Figure 43: out of the proportion by using $100 \%$ of the household head did not make use of it on project return.

Out of the proportion of fuelwood that you harvest estimate the proportion by the use you make of it for charcoal for project return.

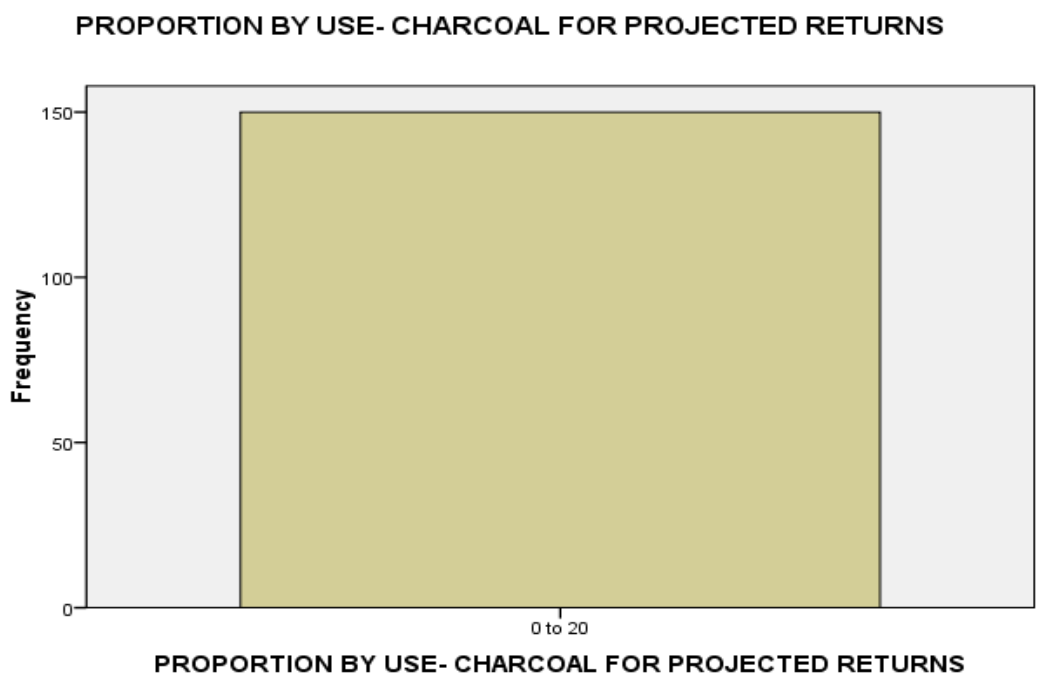

Source: Survey 2015

Figure 44: showing the proportion of fuelwood that they harvest, estimate the proportion by the use you make of it for charcoal for project return.

Figure 44: out of the proportion by using $100 \%$ of the household head did not make use of it on project return

Out of the proportion of fuelwood that you harvest estimate the proportion by the use you make of it for timber for project return. 


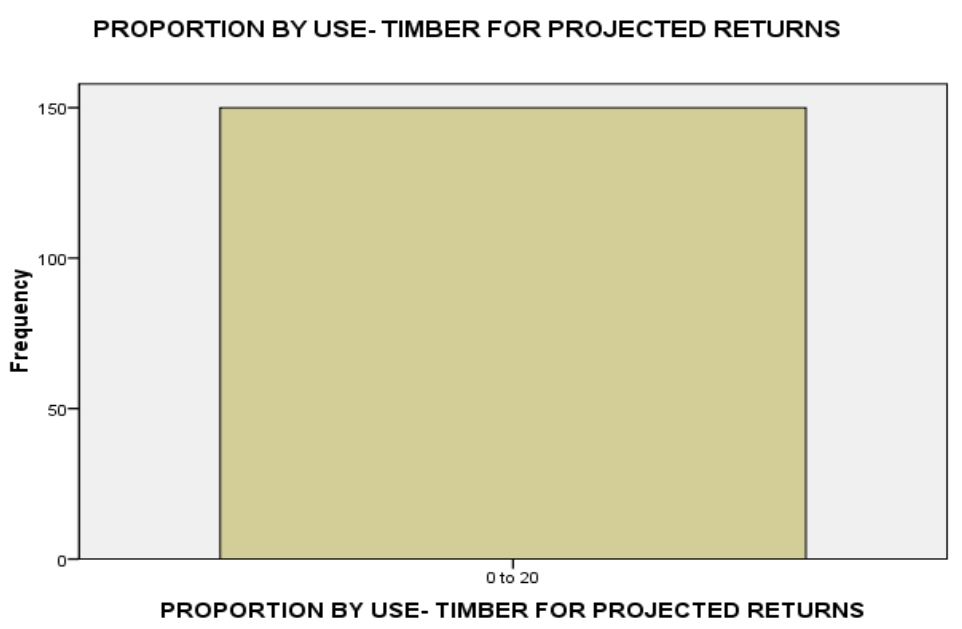

Source: Survey 2015

Figure 45: showing the proportion of fuelwood that they harvest, estimate the proportion by the use you make of it for timber for project return.

Figure 45: out of the proportion by using $100 \%$ of the household head did not make use of it on project return.

Out of the proportion of fuelwood that you harvest estimate the proportion by the use you make of it for the pole for project return.

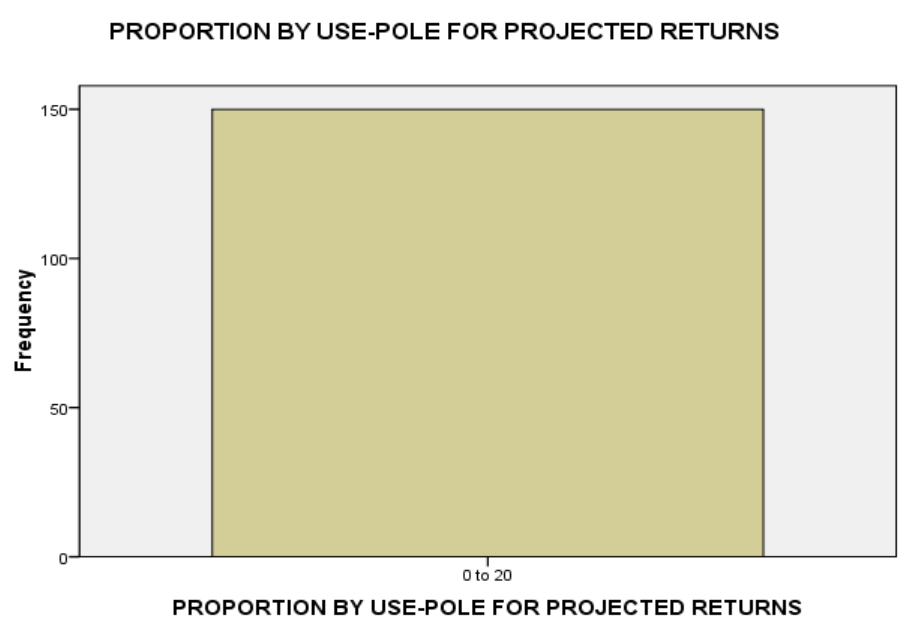

Source: Survey 2015

Figure 46: showing the proportion of fuelwood that they harvest, estimate the proportion by the use you make of it for the pole for project return. 
Figure 46: out of the proportion by using $100 \%$ of the household head did not make use of it on project return.

\section{KNOWLEDGE OF RURAL HOUSEHOLD ON CLIMATE CHANGE}

\subsubsection{Have ever heard about the expression of climate change.}

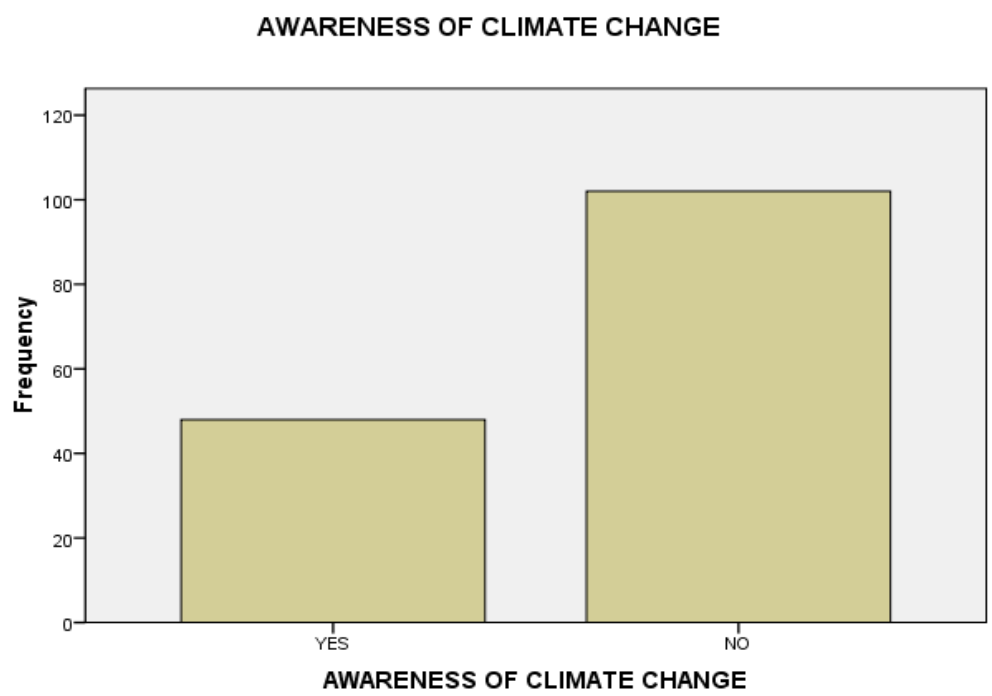

Source: Survey 2015

Figure 47: showing the level of their knowledge about expression climate change.

From the figure above $32 \%$ of the respondents say yes they are aware of the expression climate change and $68 \%$ say NO they are not aware of the expression climate change.

Expression of climate change 


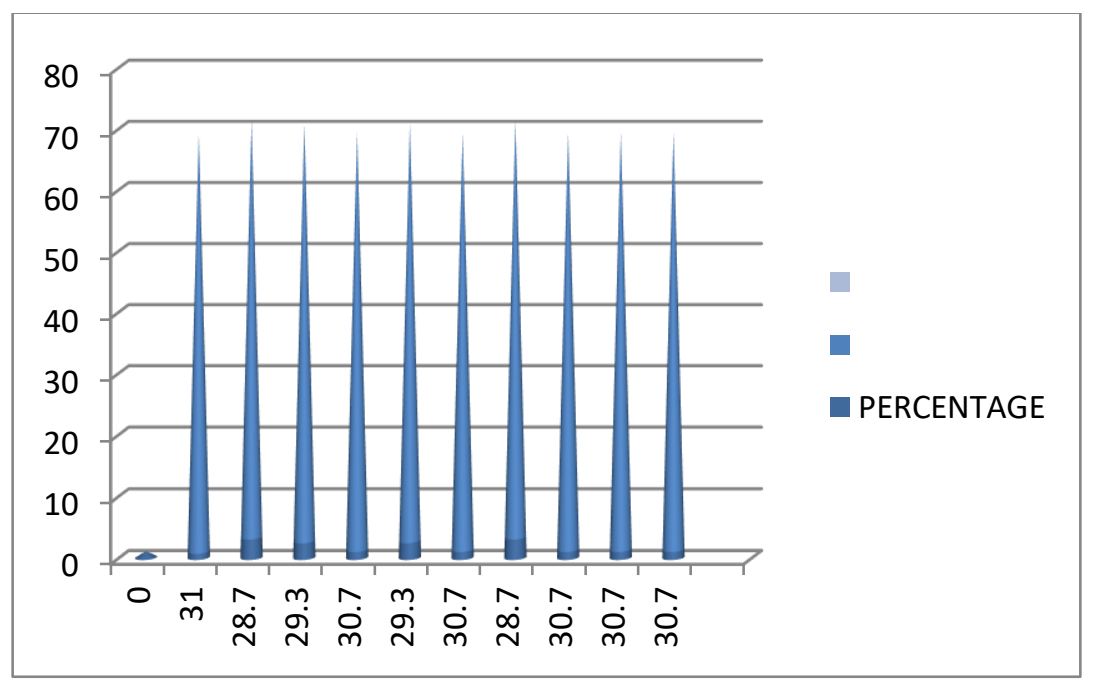

Source: survey 2015

Figure 48: showing the test result of their knowledge about the expression of climate change.

From the figure above it clearly, show that the respondents level of understanding about climate change is very poor

\section{Effect of climate change in your environment}

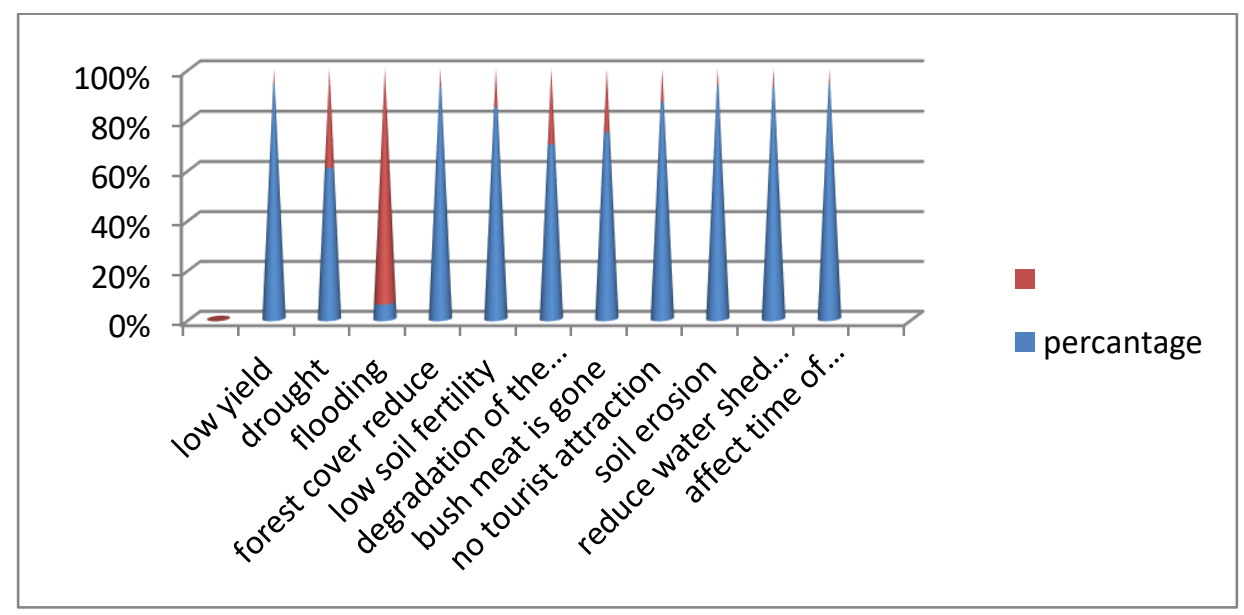

Source: Survey 2015

Figure 49: showing the effect of climate change in the environment.

Figure 49: show that climate change has a high effect on the time of planting and low effect on flooding.

\section{Household access to extension services}




\section{Extension in your community}

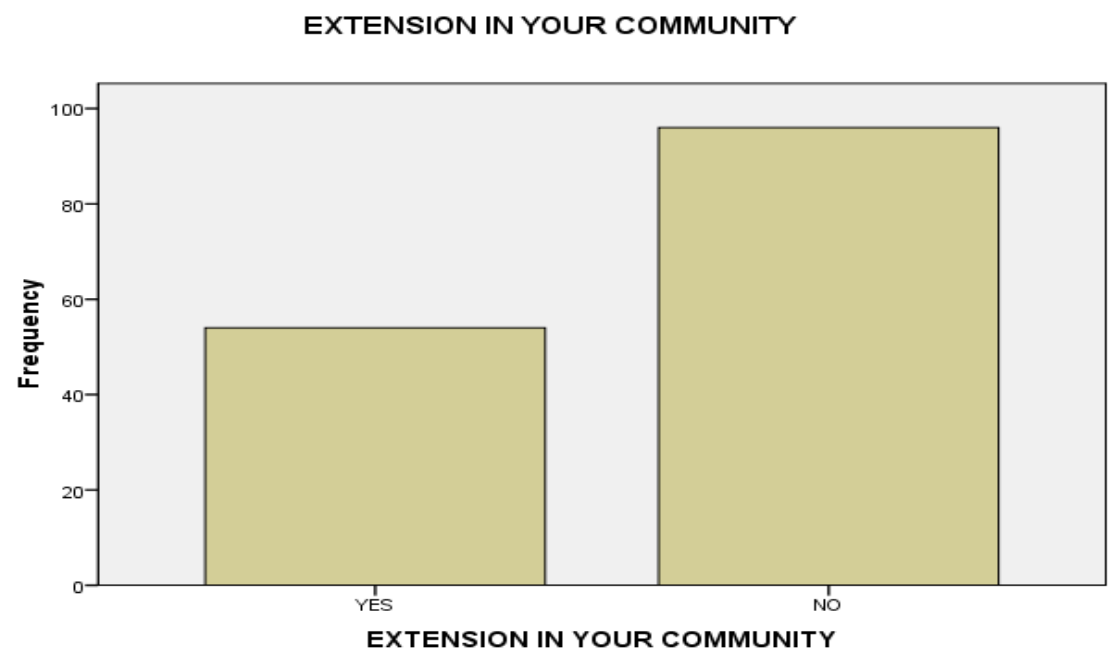

Source: Survey 2015

Figure 50: showing if there is an extension in the community.

Figure 50: shows that $36.0 \%$ of the respondent interviewed says yes there is an extension in their environment and $64.0 \%$ of the respondents interviewed say No there is no extension in their environment.

How often do you access extension in your community?

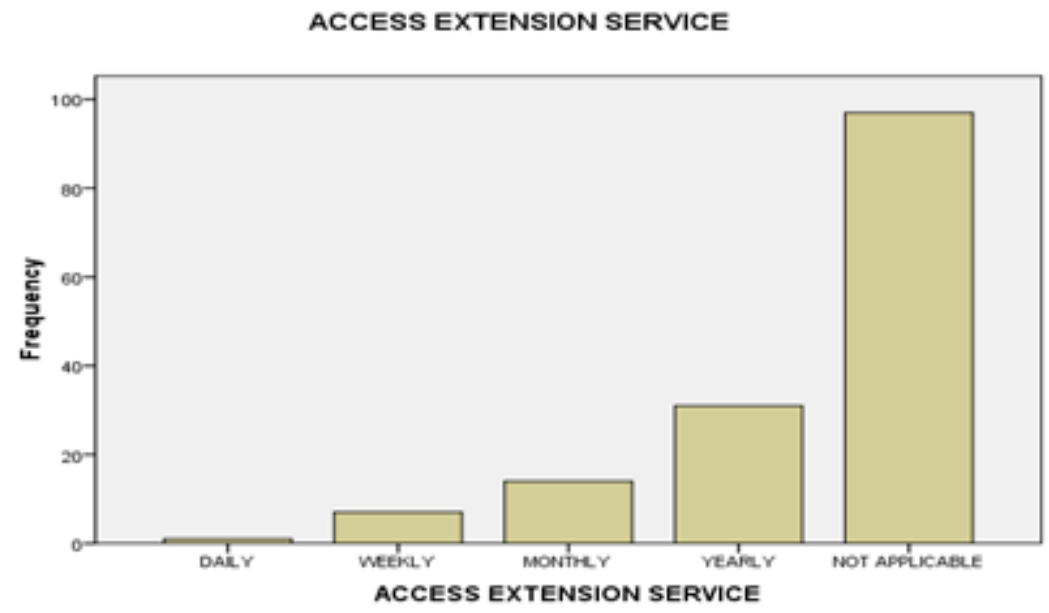

Source: Survey 2015

Figure 51: showing how often they access extension in the community. 
Figure 51: show that $7.0 \%$ of the respondent interviewed says daily,4.7\% says weekly,9.7\% says monthly, $20.7 \%$ says yearly and $64 \%$ says is not applicable because there is no extension in their community

The format which they access extension services?

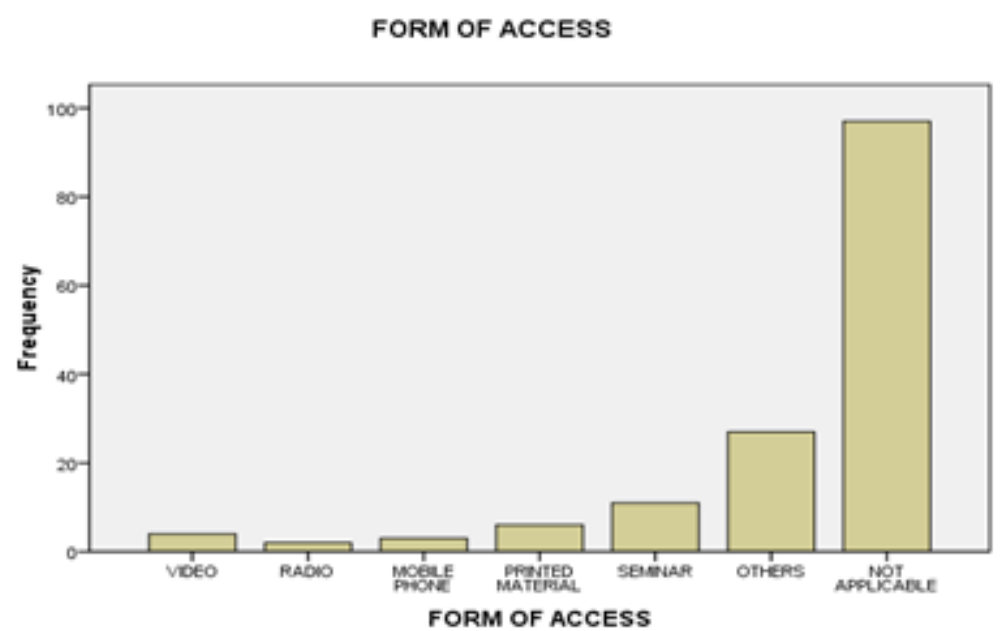

Source: Survey 2015

Figure 52: showing the form in which they access extension service in the community.

Figure 52: shows that $2.7 \%$ of the respondent interviewed says the video, $1.3 \%$ says radio, $2.0 \%$ says a mobile phone, $4.0 \%$ says printed material, $7.3 \%$ says seminar, $18 \%$ says other (Oral) and $64.7 \%$ say not applicable because there is no extension in their community.

The focus of the discussion with the extension services climate change-related issue.

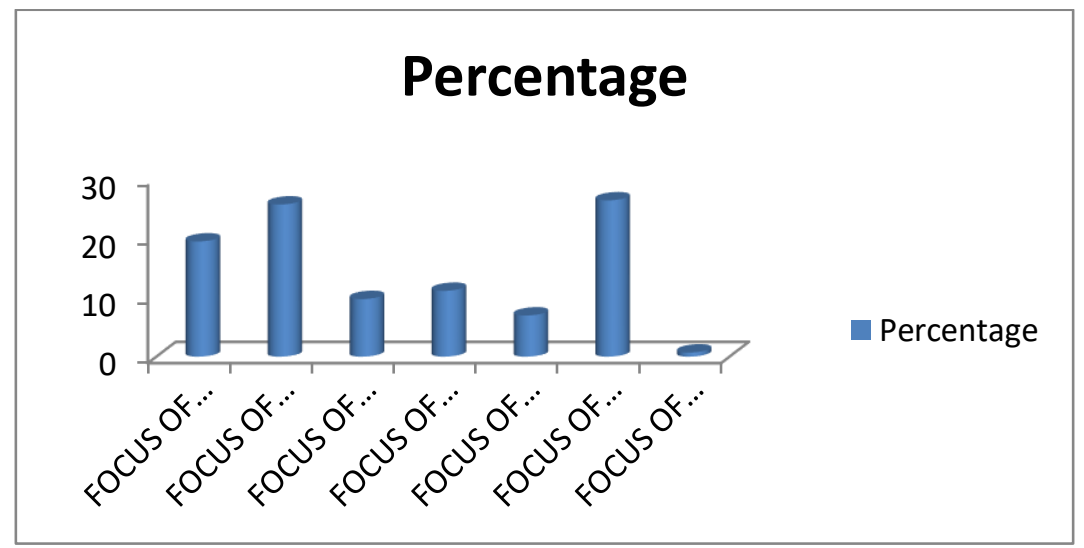

Source: Survey 2015

Figure 53: showing the focus of the discussion with the extension service. 
International Journal of Agriculture and Environmental Research

ISSN: 2455-6939

Volume: 06, Issue: 03 "May-June 2020"

Figure 53 shows that the focus of discussion with extension workers in the production and farmbased organization and there is a low focus on climate change.

\section{Discussion of the major finding}

\section{Characteristics of rural households}

The result on gender revealed that women still lag behind their male counterparts in the development initiative in the study area. Such a situation may expose a woman to make very little decisions in the development policies. this agrees with world bank (2003) finding which stated that though woman produces two-thirds of the food crops, yet men, and not a woman make the key farm management decision, sadly, female household head in Sierra Leone are among the voiceless especially concerning influencing agriculture policies which are aimed at increasing food security and food production, tend to either underestimate or ignore woman's role in both production and the general decision-making within the household.

The result of the study showed that there are more adult people engage in fuelwood harvesting. The majority of the respondent were married, this implies that the tendency of fuelwood harvesting is greater because the married couple was mostly contacted. The study revealed that the majority of the household head did not attend school, and those who were fortunate to attain a low level of education, this low level of education will affect their attitude and desire for adopting innovation. This study also did not agree with Rogers 2003, who found out that education has the potential to increase their level of understanding about the effect of climate change. According to the studies, the majority were household heads of their family and this implies that the majority of the respondents were married couples and it shows a sense of responsibility for the taking into cognizance to new knowledge and hence the tendency for adoption. The majority of the respondent have a family size of 8-13 persons. But mussel et.al (2001) reported no significant change relationship between household size and adoption. On the contrary, the study carried out by Shibah et al (2001) found a statistically significant positive relationship between the two variables, this implies that an increase in household size would lead to an increase in the adoption of knowledge. From the findings of this study, the main source of income for the majority of the people in the study area is fuelwood harvesting and combination with Agriculture. This study confirmed Kaidanehs's (1993) findings that Agriculture is the main occupation and source of income for the rural populace in Sierra Leone. This means that through agriculture there are lots of benefits gains if at all we take the career very seriously.It was also finding out that there estimate monthly income ranges between fifty thousand to two hundred and fifty thousand Leone.

From the finding of this study, most of the household head has spent almost fifteen years in their community and $38 \%$ of them are youth and Adult. 


\section{The extent of fuelwood harvesting}

Out of the five reasons for fuelwood harvesting introduced (firewood, charcoal, timber, poles, and other species). As presented in figures the majority of the households head harvested fuelwood for firewood. And most of the harvest the fuelwood for domestics use only as there is no other source of fuel for domestics use in their community. From the finding, most of them have to live in their community for several years and they depend on fuelwood harvesting.

According to the study, the majority of the household head harvest fuelwood for firewood every day, for timber not too common, for charcoal and pole same it not too common for them.

From the findings the average quantity of fuelwood harvest for firewood in one goes is 21 to $30 \mathrm{~kg}$ for timber $51 \mathrm{~kg}$, charcoal $41 \mathrm{~kg}$ to $50 \mathrm{~kg}$ and pole is $31 \mathrm{~kg}$ to $40 \mathrm{~kg}$.

From the finding, on the average households are spending 11 more minutes rep trip now to collect fuelwood, this shows that deforestation is on the rise. Out of the proportion by using most of the household head use fuelwood for domestic purposes.

\section{Knowledge of rural household on climate change}

Innovation usually brings with some degree of benefit to its potential adopters but it's equally created some kind of uncertainties in the mind of adopters(Rogers,1995).from the study there are a lot of benefits if the people knowledge of climate change is well explained to them but almost half of the total population have never heard about the expression climate change and the effect it cause in the environment. Even doe there is a low extension officer in their community their focus of discussion is not meanly on climate change.

\section{Household Access extension services}

As extension has a great role to play in people living in the community so it must be available but from the finding of this study, only very few communities have an extension and the access to it is not available the time they need it most.

According to the study, a large number of the total population comment that when rating the extension services that they receive they said it inadequate even nit applicable to them because there is no extension in their community.

\section{SUMMARY, CONCLUSION AND RECOMMENDATION}

\section{Summary}

The overall objective of the study was to assess the effect of fuelwood harvesting on the livelihood of rural households in Moyamba District, Southern Sierra Leone. The specific 
International Journal of Agriculture and Environmental Research

ISSN: 2455-6939

Volume: 06, Issue: 03 "May-June 2020"

objectives are to To describe the Characteristics of rural households that depend on fuelwood harvesting in the research area, determine the extent of fuelwood harvesting among households in the research area, assess the Knowledge of rural household on climate and Extent to which household access extension services in the research area. The study was limited in scope, instrument, the sample of household head, and study area. It was mainly limited to Kori, Kamejei, and lower Banta chiefdoms as there is a massive production of fuelwood harvesting in this area. Data collection mainly targeted household heads.

Undertaking the study, a survey research design was adopted based on which a standard questionnaire was developed. The population for this study targeted all males and females those are household heads in these chiefdoms estimated to be around 5,000 household heads. The sample size for this study was determined based on Yamane (1967) sample size determination procedure. A two-stage sampling technique was carried out to select the sample respondents. The first stage was a purposive selection of the project areas (areas mostly harvest fuelwood). The second stage was also the selection of respondents. A simple random sample technique was used to select a total number of hundred and fifty (150) household heads as the sample for the study. A survey questionnaire was chosen for the collection of information from the farmers for this study to achieve the study objectives.

The instrument was administered to the farers by the researcher himself alongside (2) trained enumerators (extension agents).

The data collected was entered and analyzed by simple descriptive analysis and simple linear regression tests using statistical package for social scientists (SPSS). The descriptive statistics involving the use of frequencies and percentages were used to summarize the data.

The major findings of this study include. Male household head dominates fuelwood harvesting in the study area, between age brackets 26 to 46years this presents the active group in fuelwood harvesting, $82.7 \%$ of the respondents were married,50.0\% of the respondents did not go to school at all, also 55.3\% of them were household heads, with the highest household size ranging from 8 13 people, from the study it is showed that majority of the household heads practice farming and fuelwood harvesting as their main source of income with a percentage of $90.0 \%$.

From the study, majority of the household hold head harvest fuelwood for firewood and it mainly for domestics' purpose and it is a daily job for them to harvest firewood with an average quantity ranging between $21 \mathrm{~kg}$ to $30 \mathrm{~kg}$ and they lack the knowledge of the effect of climate change in their environment.

There is no significant relationship between extension service to the household head and the effect of fuelwood harvesting on the livelihood of rural households in the moyamba district. 


\section{Conclusion}

Based on the findings of the study, the following conclusions are drawn:

Male household heads dominate fuelwood harvesting in the study area, indicating that women are being relegated to the background in the fuelwood harvesting system.

Majority of the household head were within the age bracket of 26 to 46 years, stating that there are more active members engaged in fuelwood harvesting and therefore need support from Government and other donor agencies to aid their Agricultural activities and deviate from fuelwood harvesting to be able to feed their families since most of them were married and have the tendency to adapt to new knowledge about the effect of climate change in their environment. Those who were not educated completely dominated among the respondent that are were interviewed this shows that the awareness and adoption of innovations are affected by the literacy status of household heads. There is an increase in the number of household head and household size of 8-13 people tend the adoption of new knowledge about the effect of fuelwood harvesting. From the study majority of the respondents, practice farming and fuelwood harvesting as their main source of income and this depicted that household head if supported there would be increased in the production of Agricultural produce because it will stop them not to do fuelwood harvesting.

According to the data, the preferences of the household heads are to improve their knowledge in the effect of climate change in their environment and each community should access extension services in their environment. There are a lot of constraints faced therefore effort is needed to assist these household heads to promote higher production of crops and to stop them from fuelwood harvesting.

\section{Recommendations}

After the conclusion drawn from this study, the following are some of the recommendations;

1. The study recommends that extension workers should receive training on climate changerelated issues. Besides, other alternatives for cooking should be made available to rural households.

2. There is no strong relationship between regular extension visit and training but the study revealed that the seldom visit of extension agents to the study area gives a clear indication that extension agents/services were not playing their roles in promoting agriculture and help the people to stop fuelwood harvesting in the study area. The study recommends that regular visitor contact with extension services provide an opportunity for transfer of skills, knowledge of climate change, and other information which discourages them from fuelwood harvesting. 
3. According to what the study revealed, the excess harvesting of fuelwood is faced as a result of inaccessibility to another source of fuel for their domestic purposes, therefore the study demanded the government, stakeholder and donor agency join together and bring up another means of fuel that household will use for domestics purpose.

Government and stakeholder should encourage men as well as woman participation in the fight against climate change and also increase the extension contact and participation in handling this problem in the world

\section{REFERENCES}

Adebajo Oyefunke Ooyemi (2012).Effect of Family Size on Household Food Security in Ogun State, Nigeria. Department of Agricultural Economic Extension. Ladoke Akintala University of Technology, Ogbomosho Nigeria. Vol 2 No 2, pp 137-138

Aruna Agrawal (2008). The role of local institutions in the adoption of climate change. A paper prepared for social dimensions of climate change, social development department world bank. pp 9-31

Bernard Chazovachii, Leonard Chitongo, and Jenias Ndava, (2013).Reducing urban poverty through fuelwood business in Masvingo city, zimbabwe. Bangladesh e-journal of sociology volume 10 number 1 .p 60

Canberra Group Hand Book on Household Income Statistics, Second Edition. Pp 6-17

Dr. M. Khata Jabor et al (2011) Does Parent Educational Status Matter on the Students Achievement in Science. International Conference on Social Science and Humanity, Lacsit Press Singapore Vol.5 pp 309-310

D. Kupter (Germany, fed Rep) and R. Koriman Zira (zimbabwe), (1990). Agriculture, Forestry and other Human activities pp 77-78

F.E.Ebe, (2014). The sources, distribution channel, and market structure of fuelwood in Enugu state, Nigeria. Journal of economics and finance volume 5 issue 6 p30.

Francis Libois and Vincent Sumville (2014) Fertility, household size, and poverty in Nepal.CMI working paper.vol 4.pp 5-14

Jonah. M. Fogel,(2013).Collaborative interface modeling of fuelwood harvesting practices. Residential NIPF landowners of the Jefferson national forest wildland-urban interface, Montgomery country Virginia. 
Kyle .W. Knight and Eugene .A. Rosa,(2014). Household dynamic and fuelwood consumption in developing countries: a cross-national analysis.p378.

Kampal Sinha (2005) Household characteristics and calorie intake in rural India. Quantile Regression Approach. the Australian national university.pp2-23.

Linda. C. Gallo et al(2003).Martial Status and Quality in Middle Age Woman. Association with Levels and Trajectories of Cardiovascular Risk Factors. America Psychological Association Inc. Vol 22. pp 453-463

M. Arnold and R. persson (2003). Reassessing the fuelwood situation in developing countries. International forest review Swedish University of Agricultural Sciences Department of forest product and market. p.o.box 7060,75007 Uppsala, Sweden pp 379.

Matt Barnes and Abigail McKnight et al (2014). Understanding the Behaviours of Household Influence Poverty. A Review of Research Evidence, Department of Energy, and Climate Change. Nat Social Research.

Mohammed. B.T and Abdulguadri. A.F (2013). Comparative Analysis of Gender Involvement in Agricultural Production and Agricultural Economic Vol 4(8), pp 240-244

O.A Oni and S.A. Yusuf (2007). Determinants of expected poverty among rural households in Nigeria. Department of Agricultural Economics, University of Ibadan. Ibadan Nigeria.

Paul Munro (2011).The Domestic Trade in Timber and Fuelwood product in Sierra Leone. pp 6 